Review Article

\title{
Aminoquinolines as Translational Models for Drug Repurposing: Anticancer Adjuvant Properties and Toxicokinetic-Related Features
}

\author{
Paulo Michel Pinheiro Ferreira $\left(\mathbb{D},{ }^{1}\right.$ José Roberto de Oliveira Ferreira $\left(\mathbb{D},{ }^{2}\right.$ \\ Rayran Walter Ramos de Sousa $\mathbb{D}^{1},{ }^{1}$ Daniel Pereira Bezerra $\left(\mathbb{D},{ }^{3}\right.$ \\ and Gardenia Carmen Gadelha Militão (iD ${ }^{4}$ \\ ${ }^{1}$ Department of Biophysics and Physiology, Laboratory of Experimental Cancerology (LabCancer), Federal University of Piauí, \\ Teresina 64049-550, Brazil \\ ${ }^{2}$ Center for Integrative Sciences, State University of Health Sciences of Alagoas, Maceió 57010-382, Brazil \\ ${ }^{3}$ Gonçalo Moniz Institute, Oswaldo Cruz Foundation (IGM-FIOCRUZ-BA), Salvador 40296-710, Brazil \\ ${ }^{4}$ Department of Physiology and Pharmacology, Federal University of Pernambuco, Recife 50670-901, Brazil
}

Correspondence should be addressed to Paulo Michel Pinheiro Ferreira; pmpf@ufpi.edu.br

Received 21 June 2021; Accepted 21 August 2021; Published 6 September 2021

Academic Editor: Tian Li

Copyright (c) 2021 Paulo Michel Pinheiro Ferreira et al. This is an open access article distributed under the Creative Commons Attribution License, which permits unrestricted use, distribution, and reproduction in any medium, provided the original work is properly cited.

\begin{abstract}
The indiscriminate consumption of antimalarials against coronavirus disease-2019 emphasizes the longstanding clinical weapons of medicines. In this work, we conducted a review on the antitumor mechanisms of aminoquinolines, focusing on the responses and differences of tumor histological tissues and toxicity related to pharmacokinetics. This well-defined analysis shows similar mechanistic forms triggered by aminoquinolines in different histological tumor tissues and under coexposure conditions, although different pharmacological potencies also occur. These molecules are lysosomotropic amines that increase the antiproliferative action of chemotherapeutic agents, mainly by cell cycle arrest, histone acetylation, physiological changes in tyrosine kinase metabolism, inhibition of PI3K/Akt/mTOR pathways, cyclin D1, E2F1, angiogenesis, ribosome biogenesis, triggering of ATM-ATR/p53/p21 signaling, apoptosis, and presentation of tumor peptides. Their chemo/radiotherapy sensitization effects may be an adjuvant option against solid tumors, since 4-aminoquinolines induce lysosomal-mediated programmed cytotoxicity of cancer cells and accumulation of key markers, predominantly, LAMP1, p62/SQSTM1, LC3 members, GAPDH, beclin-1/Atg6, $\alpha$-synuclein, and granules of lipofuscin. Adverse effects are dose-dependent, though most common with chloroquine, hydroxychloroquine, amodiaquine, and other aminoquinolines are gastrointestinal changes, blurred vision ventricular arrhythmias, cardiac arrest, QTc prolongation, severe hypoglycemia with loss of consciousness, and retinopathy, and they are more common with chloroquine than with hydroxychloroquine and amodiaquine due to pharmacokinetic features. Additionally, psychological/neurological effects were also detected during acute or chronic use, but aminoquinolines do not cross the placenta easily and low quantity is found in breast milk despite their long mean residence times, which depends on the coexistence of hepatic diseases (cancer-related or not), first pass metabolism, and comedications. The low cost and availability on the world market have converted aminoquinolines into "star drugs" for pharmaceutical repurposing, but a continuous pharmacovigilance is necessary because these antimalarials have multiple modes of action/unwanted targets, relatively narrow therapeutic windows, recurrent adverse effects, and related poisoning self-treatment. Therefore, their use must obey strict rules, ethical and medical prescriptions, and clinical and laboratory monitoring.
\end{abstract}




\section{Introduction}

Globally, about 1 in 6 deaths is due to cancer and about $70 \%$ of cancer deaths occur in low- and middle-income countries. Approximately, one third of these deaths are associated with high body mass index, low consumption of fruits and vegetables, lack of physical activity, and use of tobacco and alcohol. Tobacco use is the most important risk factor for cancer and accounts for approximately $22 \%$ of the total deaths. On the other hand, infections such as hepatitis and human papilloma virus (HPV) are responsible for up to $25 \%$ of cancer cases in poor and developing countries. In 2018 alone, approximately 9.6 million deaths were related to cancer [1-3].

Determining treatment and palliative care goals are critical steps for cancer therapy with integrated and peoplecentered health services [3]. Even with a variety of options to treat sarcomas, carcinomas, and adenocarcinomas, such as antimetabolites, microtubule inhibitors, DNA intercalators [4], and monoclonal antibodies [5], resistance remains the cause central to therapeutic failures as well as adverse side effects [6].

In this context, the synthesis and identification of strategic molecules is essential if we want low cost, efficiency, and speed in the production of valuable chemotherapy molecules. Here, we can include aminoquinoline compounds that have the amino group at position 4 of the quinoline ring system. These compounds include molecules used in the treatment of first line (amodiaquine and chloroquine), recurrence (tafenoquine), uncomplicated (hydroxychloroquine) and prevention (chloroquine, hydroxychloroquine and tafenoquine) of malaria infections by Plasmodium vivax, $P$. malariae, $P$. ovale, and P. falciparum [7-9].

In December 2019, a new severe acute respiratory syndrome coronavirus-2 (called SARS-CoV-2) emerged in China and led to the coronavirus-related pandemic in 2019 (COVID-19) [10]. The indiscriminate use of chloroquine and hydroxychloroquine as a first-line, adjuvant, or palliative drug(s) to treat victims of COVID-19 or to control new local outbreaks as a prophylactic $[11,12]$ emphasized the various longstanding clinical branches of drugs, including those against chronic disorders. Advantages such as low cost, long usage history, and market availability even in developing countries where malaria is endemic are reasons that explain, at least in part, the commercial triumph of these drugs, converting 4-aminoquinolines into "star drugs" for their reuse in the pharmaceutical industry. Then, we performed a review on the anti-tumor mechanisms of aminoquinolines, focusing on the responses and differences of histological tumor tissues and on the aspects of toxicity related to pharmacokinetics.

To carry out a comprehensive and consistent analysis, we use only primary and secondary materials, including research articles, reviews, books, and government publications written in English, Portuguese, or Spanish. The bibliographic research was performed in the scientific databases ScienceDirect, Scopus, PubMed, and Scielo. The descriptors “autophagy," “cell cycle," “apoptosis," “drug repurposing”, and "anti-tumor" were combined with "aminoquinoline" for a narrative scientific exploration.

\section{Main Text}

2.1. Drug Repurposing for Anticancer Agents: Need or Pharmaceutical Business? Less toxic and more effective treatment designs are often the main reasons for redirections, considering previously recorded aspects of preclinical and clinical pharmacodynamics and toxicokinetics, making drug reuse faster [13-15].

Examples of reuse of effective anticancer drugs in advanced preclinical or clinical studies are almost immeasurable. As a typical example, thalidomide is a leading molecule that has been marketed in 1956 in West Germany, first as antiflu and in 1957 as an antiemetic for pregnancy, but has now been repurposed and approved for multiple myeloma [16, 17]; itraconazole, a triazole antifungal developed in the 1980s, showed anticancer activities in preclinical in vitro and in vivo models of pancreatic ductal adenocarcinoma derived from liver metastasis [18]; disulfiram, initially approved to mitigate alcoholism, has been investigated to treat radiation-resistant breast cancer stem cells [19]; nelfinavir, originally indicated for the treatment of HIV infection, also exhibits synergistic effects against human cervical cancer cells [20]; sildenafil, which failed in phase II clinical trials for angina disorders, has been redirected to the treatment of erectile dysfunctions and sensitizes prostate cancer cells to doxorubicin-mediated apoptosis [21]; mebendazole, a broad spectrum anthelmintic developed for the treatment of veterinary parasites, has advanced from the treatment of animals to the first clinical applications in humans, inhibiting the growth of adrenocortical carcinoma, gastric cancer, medulloblastoma, glioblastoma, leukemia and myeloma, and breast and prostate cancers [22]; metformin, a classic hypoglycemic medication for diabetes, has revealed a new identity as an antitumor activity by suppressing the mammalian target of rapamycin (mTOR) in human cervical cancer [20] and acute myeloid leukemia [23], and valproic acid, an anticonvulsant that has been considered in several clinical trials due to its epigenetic properties, inhibition of histone deacetylase, and induction of autophagy in neoplastic stomach cells [24].

In 1934, the first synthetized aminoquinolinechloroquine [4-N-(7-chloroquinolin-4-yl)-1-N,1-N-diethylpentane-1,4-diamine]-was based on the quinine structure isolated from Cinchona officinalis barks in the 1800s. In 1946, hydroxychloroquine [2-[[(4S)-4-[(7-chloroquinolin-4-yl) amino]pentyl]-ethylamino]ethanol] was synthesized, and both molecules were developed as antimalarial tools (Figure 1), as well as extra 4- and 8-aminoquinolines (amodiaquine, tafenoquine, primaquine, mefloquine, quinacrine, quinine, quinidine, and 8-hydroxyquinoline and artemisinin) in an attempt to overcome resistance in Plasmodium species, and the side effects $[8,25,26]$ seem similar to that of cancer therapy, whose initial successful single-target therapies have been replaced by more combined efficient protocols.

Currently, the aminoquinolines, chloroquine phosphate and hydroxychloroquine sulphate, have been the most 


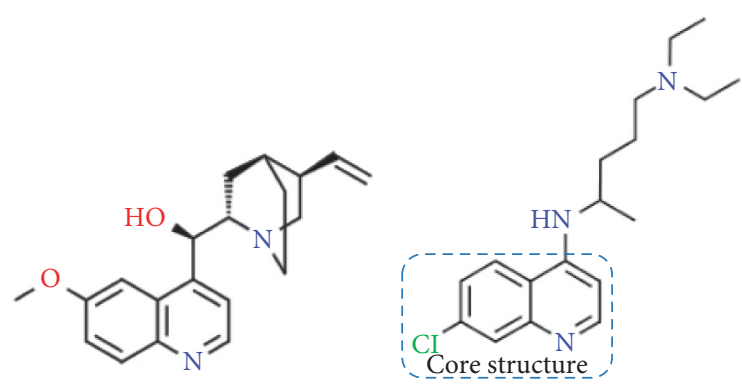

Quinine
Chloroquine

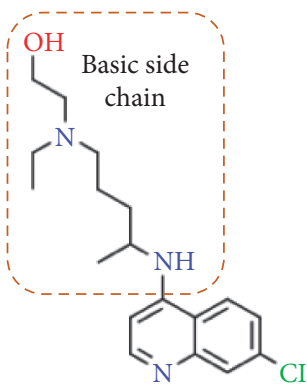

Hydroxychloroquine

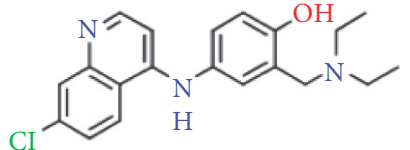

Amodiaquine<smiles>C=CC1CN2CCC1CC2[C@H](O)c1ccnc2ccc(OC)cc12</smiles>

Quinidine

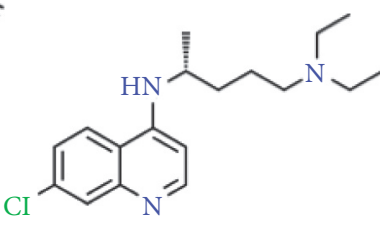

Primaquine

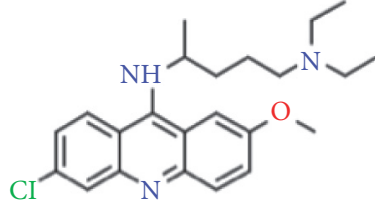

Quinacrine

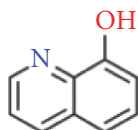

8-hydroxyquinoline

FIGURE 1: Structures of some common aminoquinolines in clinical use as antimalarials or anti-inflammatory drugs and under investigations as anticancer agents.

common salts used [27] as the first-line regimen for the radical cure of malaria by $P$. vivax in most regions [26] and to treat acute and chronic inflammatory conditions $[9,28-30]$, respectively, although primaquine and amodiaquine, when used alone or in combination with artemisinin, provide adequate efficacy against many chloroquine-resistant parasites $[8,26]$.

\subsection{Antiproliferative Mechanism of Aminoquinolines.} More than 50 years ago, chloroquine showed promising cytotoxicity of tumor cells in vitro [31], but only in the last two decades, studies with chloroquine, hydroxychloroquine, and related molecules demonstrated lysosomal-mediated cell death in cancer cells. The exact mechanism of cytotoxic action is not yet fully understood, but hypothesis have attempted.

These molecules can enter into endosomes/lysosomes by passive diffusion, or they can be taken up together with sodium in the exchange of protons, as demonstrated by specific inhibitors of eukaryotic membrane $\mathrm{Na}^{+} / \mathrm{H}^{+}$exchangers (NHE) [32]. Both converge in the accumulation within endosomes/lysosomes, leading to the interference of the autophagic flux [33-35], disruption of several enzymes (e.g., acid hydrolases and cathepsin B and D lysosomal cysteine proteases) [36,37], inhibition of antigen processing $[38,39]$, and post-translational modification of recently produced proteins $[35,40]$. In addition, preclinical and clinical investigations are testing the effectiveness of quinines as inhibitors of the autophagy flux to overcome resistance when traditional chemotherapy drugs are used as monotherapy, since the induction of autophagy has been associated with resistance in the therapy of cancer [41, 42].

2.2.1. Brain Tumor Cells. Chloroquine decreases cell proliferation of p53 wild-type glioma lines more efficiently, indicating a key p53 responsibility for apoptotic cell death and cell cycle control through the HDM2, P21, PIG3, and $B A X$ genes (Figure 2). Likewise, the induction of apoptosis in vivo was found in mice with U87MG glioma intracranially when treated with chloroquine [43].

On the other hand, chloroquine-induced neuronal cell death of normal neurons [44] indicates mitochondrial dysfunction as a result of p53-independent effects [43], but dependent on cathepsin D lysosomal cysteine proteases processing, proposing direct or indirect actions on the cathepsin D metabolism [37]. Moreover, chloroquine activation of ataxia telangiectasia-mutated (ATM)/ataxia telangiectasia and Rad3-related (ATR) kinase DNA injuries [45] seems unnecessary for caspases and p53 activation $[37,43,44,46-48]$, suggesting that aminoquinolines induce the death of glioblastoma cells, regardless of the p53 status [37].

The absence of DNA damage induced by chloroquine similar to DNA damage by direct ionizing radiation with consequent activation of p53 can be associated with its mechanism of interaction with DNA molecules, since chloroquine intercalates into DNA, but does not cause DNA damage directly $[43,49]$; this does not exclude that caspase- 3 activation is stronger in wild-type p53 glioma cells, proposing a clear contribution of p53 to chloroquine-induced apoptosis [43].

U251-MG brain cell line, orthotopic GL-261 gliomas, or rat brain-implanted C6 cells treated with suberoylanilide hydroxamic (histone deacetylase inhibitor, HDACi) and temozolomide (alkylating agent) in the presence of chloroquine $10-15 \mu \mathrm{M}$ showed reduced cell viability, morphology changes, increase in the sub- $G_{1}$ population, Bax, cleaved-caspase-3, and cleaved-PARP1 [poly-(ADP-ribose)polymerase 1], externalization of phosphatidylserine, and activation of caspase-3/7 (Table 1). Such events are features of apoptosis, but the time course curves showed that the 


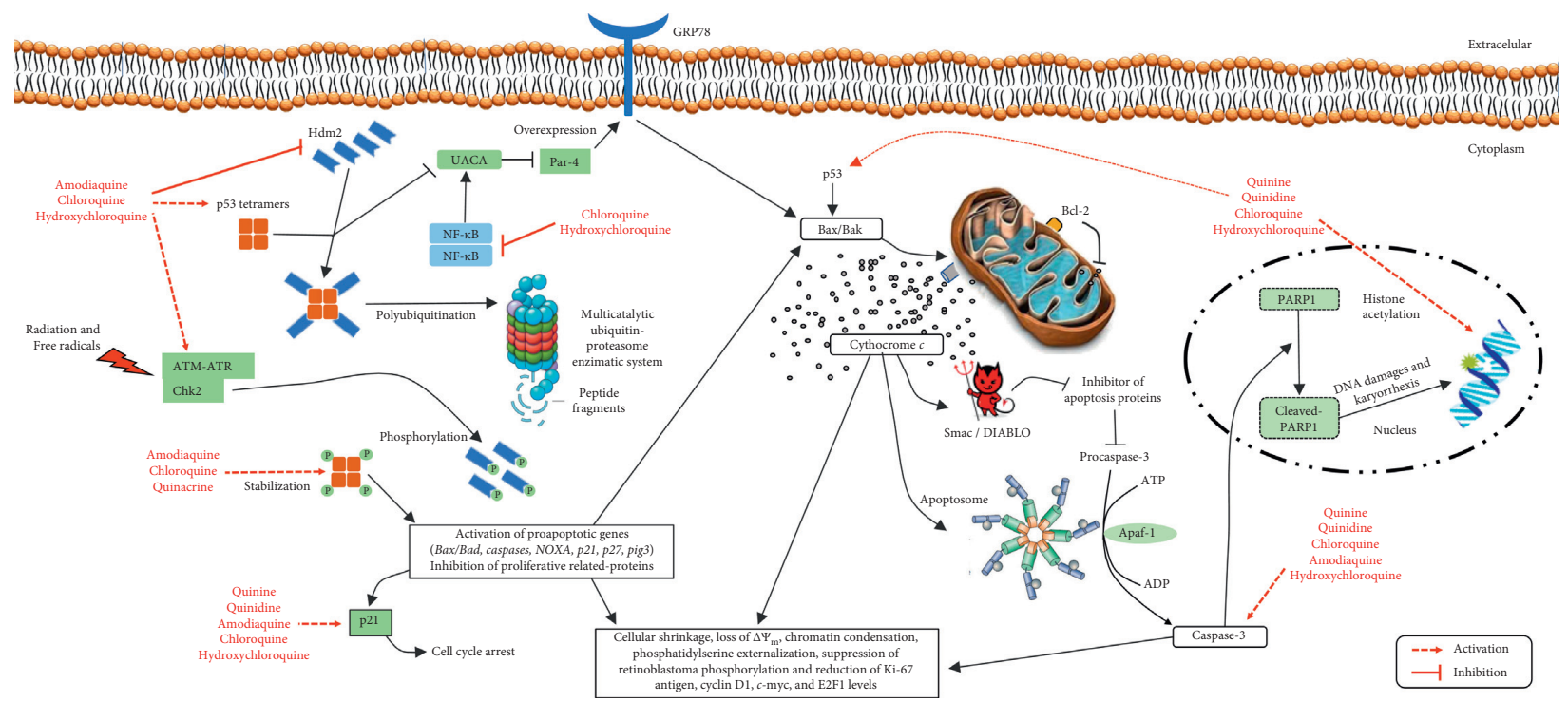

Figure 2: Pathways involved in general cytotoxicity and activation of apoptosis by 4 -aminoquinolines. The transportation of both drugs is completely via passive diffusion (i.e., no transporters are involved). Bak and Bax are p53-induced proapoptotic members that constitute the apoptotic pore complex for the release of mitochondrial cytochrome $c$, leading to mitochondrial depolarization, activation of caspase-3, cleaving of poly-(ADP-ribose)-polymerase 1 (PARP-1), and nuclear DNA fragmentation. Aminoquinoline-dependent DNA damage activates p53 and its downstream gene p21, resulting in cell cycle arrest after a post-translational p53 activation by phosphorylation of the ataxia telangiectasia-mutated (ATM) protein, leading to ATM-dependent phosphorylation of p53 checkpoint protein kinase. Moreover, chloroquine, quinacrine, and amodiaquine trigger p53 stabilization in TP53-specific reporter human cancer cells and block the p53 ubiquitination properties of human double minute $2(\mathrm{Hdm} 2)$ molecules, which in turn prevents p53 proteasome degradation. Stimulation of histone acetyltransferase (HAC) and inhibition of histone deacetylase (HDAC) are part of the rationale pattern of arresting growth. Chloroquine is linked to the activation of $\mathrm{p} 53$, inhibition of NF- $\kappa \mathrm{B}$ (factor nuclear kappa B) and uveal autoantigen with coiled-coil domains and ankyrin repeats (UACA), which promotes secretion of prostate apoptosis response-4 (Par-4) and expression of glucose regulated protein 78 (GRP78) receptor on the cancer cell surface, and consequent apoptosis.

$\mathrm{G}_{2} / \mathrm{M}$ arrest occurs with autophagy and before the apoptosis because the blocking of this response with autophagy inhibitors (3-methyladenine and chloroquine, for example) makes cells susceptible to temozolomide and suberoylanilide hydroxamic $[54,60]$.

2.2.2. Human Cervical Tumors. Human papilloma positive HeLa cells (p53 wild-type) are resistant to apoptosis-inducing effects of death receptors [64], but pretreatment with $75 \mu \mathrm{M}$ chloroquine sensitized HeLa cells towards apoptosis mediated by Fas, as measured by TUNEL staining of DNA strand breaks [65], due to the disruption of mitogen-activated protein kinases (MAPK)/extracellular signal-regulated kinases (ERK)1/2, as found in cells treated with PD98059, a MEK1 inhibitor. Indeed, chloroquine and analogues appear to disable members upstream of the MAPK pathway (Figure 3), avoiding ERK phosphorylation and activation by a paradoxical Raf phosphorylation in specific residues, which possibly blocks the ERK activation by Akt activity [65].

HELa cells treated with $10-30 \mu \mathrm{g} / \mathrm{mL}$ of hydroxychloroquine presented an increase in lysosomal volume and cathepsin B release from lysosomes to the cytosol and the nucleus, resulting in cytoplasmic vacuolization, cellular shrinkage, exposure of phosphatidylserine, loss of mitochondrial transmembrane potential $(\Delta \Psi m)$, release of cytochrome c, activation of caspase-3 (Figure 2), and condensation of chromatin. In particular, vacuolization was found before chromatin condensation and was accompanied by the signs of macroautophagy [36]. These effects were blocked by bafilomycin $\mathrm{A} 1$, which prevents degradation of LC3, induces its accumulation in autophagolysosomes [66] and acts as an inhibitor of the vacuolar-type $\mathrm{H}^{+}$-ATPase, changing endosomal $\mathrm{pH}$ [67], showing that hydroxychloroquine activated apoptosis via lysosomes instead of other organelles (mitochondria or nuclei, for example).

The colorimetric MTT assay indicated that 3-methyladenine (3-MA) or chloroquine separately has no significant effects on the viability of HeLa cells, but both enhance the cytotoxic effects of cisplatin. The cotreatment also increased the expression of p62, the levels of cleaved caspase-3/-4, caused inhibition of autophagy downstream, and accumulation of ubiquitinated beclin-1 and LC3II misfolded proteins, and almost simultaneous apoptotic activation. Since cisplatin induces the generation of misfolded proteins, but increases autophagy, this would alleviate the physiological stress of endoplasmic reticulum by clearing the ubiquitinated proteins, which would trigger intrinsic apoptosis in HeLa cells [55]. The compound 3-MA is an inhibitor of phosphatidylinositol 3-kinases, which play an important role in controlling the activation of mTOR, a key regulator of autophagy [68].

2.2.3. Colorectal Cancers. As a pyrimidine analogue, 5fluorouracil (5-FU) acts as an antimetabolite to inhibit DNA 
TABLE 1: General mechanisms of chemosensitizing and radiosensitizing adjuvant actions of chloroquine, hydroxychloroquine, and analogues.

\begin{tabular}{|c|c|c|}
\hline Treatment/Drug & Adjuvant actions & References \\
\hline $\begin{array}{l}\text { Phosphatidylinositol analogs, oligopeptides Akt-PH linkers, } \\
\text { inhibitors of Akt-kinase, and blockers of ATP-binding site } \\
\text { catalytic subunit }\end{array}$ & Mediated chemosensitization and enhanced cytotoxicity & {$[50]$} \\
\hline All-trans retinoic acid & $\begin{array}{l}\text { Reduction of Ki67-positive cells and clonogenicity, activation } \\
\text { of histone acetyltransferase, and inhibition of histone } \\
\text { deacetylase enzymes }\end{array}$ & {$[51]$} \\
\hline 5-Fluorouracil & $\begin{array}{l}\text { Down-regulation of CDK- } 2 \text { expression and cyclin E/CDK2 } \\
\text { complex activity, arrest in } G_{0} / G_{1} \text { phase, and enhancement of } \\
\text { antiproliferative properties }\end{array}$ & {$[52]$} \\
\hline Everolimus & $\begin{array}{l}\text { Proliferative reduction, increase of p53 and p } 21^{\mathrm{Cip} 1} \text { levels, } \\
\text { phosphorylation reduction at serine } 2448 \text { in mTOR proteins }\end{array}$ & {$[48]$} \\
\hline Rapamycin & $\begin{array}{c}\text { Blockade of autophagy and LC3-II degradation, cytotoxic } \\
\text { chemosensitization and involvement of a caspase- } \\
\text { independent mechanism }\end{array}$ & {$[53]$} \\
\hline Cisplatin & $\begin{array}{l}\text { Increase of caspase- } 3 \text { activation, LC3 II ubiquitinated } \\
\text { intracellular misfolded proteins, and intrinsic apoptosis }\end{array}$ & {$[54,55]$} \\
\hline Docetaxel & $\begin{array}{c}\text { Enhanced cytotoxicity and stronger in vivo anti-tumor } \\
\text { efficacy }\end{array}$ & {$[56]$} \\
\hline Doxorubicin & Potentiated cytotoxicity upon coexposure & [57] \\
\hline Oxilaplatin & $\begin{array}{l}\text { Increased sensitivity under hypoxic conditions and p62 levels, } \\
\text { delaying of tumor growth of HT-29 colon cancer xenografts }\end{array}$ & {$[58]$} \\
\hline Sunitinib & $\begin{array}{c}\text { Increase of the p62 level, reduction of blood vessel formation, } \\
\text { CD-34 expression, microvessel density, and nitric oxide levels } \\
\text { in tumor, and Ehrlich ascites carcinoma tumor growth } \\
\text { reduction }\end{array}$ & [59] \\
\hline Temozolomide & $\begin{array}{l}\text { Cell viability reduction and intensification of cleaved- } \\
\text { caspase-3, cleaved-PARP1, phosphatidylserine } \\
\text { externalization, and caspase-3/7 activation }\end{array}$ & {$[54,60]$} \\
\hline Receptor-interacting protein kinase 3 (RIP3) & $\begin{array}{l}\text { Upregulation of RIP3, accumulation of RIP3-p62 complexes } \\
\text { and type II-LC3B, and efficiency on colon tumor-bearing } \\
\text { mice }\end{array}$ & {$[61]$} \\
\hline Bevacizumab & $\begin{array}{l}\text { Weakening of the Akt-mTOR signaling pathway and } \\
\text { recovering the tumor-suppressive effect of bevacizumab }\end{array}$ & {$[62]$} \\
\hline Sertraline + erlotinib & $\begin{array}{l}\text { Amplification of caspase-independent autophagic cell death } \\
\text { and mouse survival in orthotopic non-small cell lung cancer } \\
\text { mouse models }\end{array}$ & [63] \\
\hline
\end{tabular}

and RNA synthesis, but it also has radiosensitizing, immunosuppressive, and mutational properties and has been widely used to treat various solid tumors, including colorectal, breast, stomach, pancreas, ovary, bladder, and liver cancers [69]. The apoptotic effects of 5-FU on human colorectal adenocarcinoma HT-29 cells were also increased by chloroquine. The pretreatment of HT-29 cells with chloroquine suppressed CDK-2 expression and catalytic activity of cyclin E/CDK2 complexes (Figure 2), leading to the $\left(G_{0} / G_{1}\right)$ arrest [52]. Such findings suppose autophagy as a protective route against the action of 5-FU, since autophagic inhibitors increase the antiproliferative properties of this fluoropyrimidine.

Murine cell lines showing endogenous upregulation of receptor-interacting protein kinase 3 (RIP3) were more sensitive to chloroquine [61] and presented cytosolic accumulation of RIP3-p62 complexes and LC3-II, which is commonly recruited to phagosome membranes. However, initial/executioner caspase levels are apparently not altered by chloroquine during necroptotic cell death in CT-26 cells [61].
Since the morphological and flow cytometric investigations of chloroquine-treated CT-26 cells showed dissolved nuclei, condensation, swelling of organelles, and rupture of the cell membrane, these findings suggested that, instead of apoptosis, RIP3-dependent necroptosis was probably a reason for $\mathrm{RIP3}^{+}$-chloroquine-induced cell death $[61,70,71]$.

The induction of tumor apoptosis in vivo exposed that apoptosis is not the only way by which chloroquine activates death cascade, as verified by TUNEL experiments and signals of necroptosis. In any case, mice with a CT-26-tumor xenograft showed tumor reduction after adjuvant treatments, whereas chloroquine alone showed a $45 \%$ reduction, and the combination with chemotherapies increased by up to $80 \%$ [61].

Chloroquine plus sunitinib, bevacizumab, and/or oxaliplatin increased intracellular levels of p62, indicating the accumulation and interruption of autophagic flux, increased caspase-3 activity and sensitivity under hypoxia conditions, and reduced blood vessel formation, expression of CD31, 


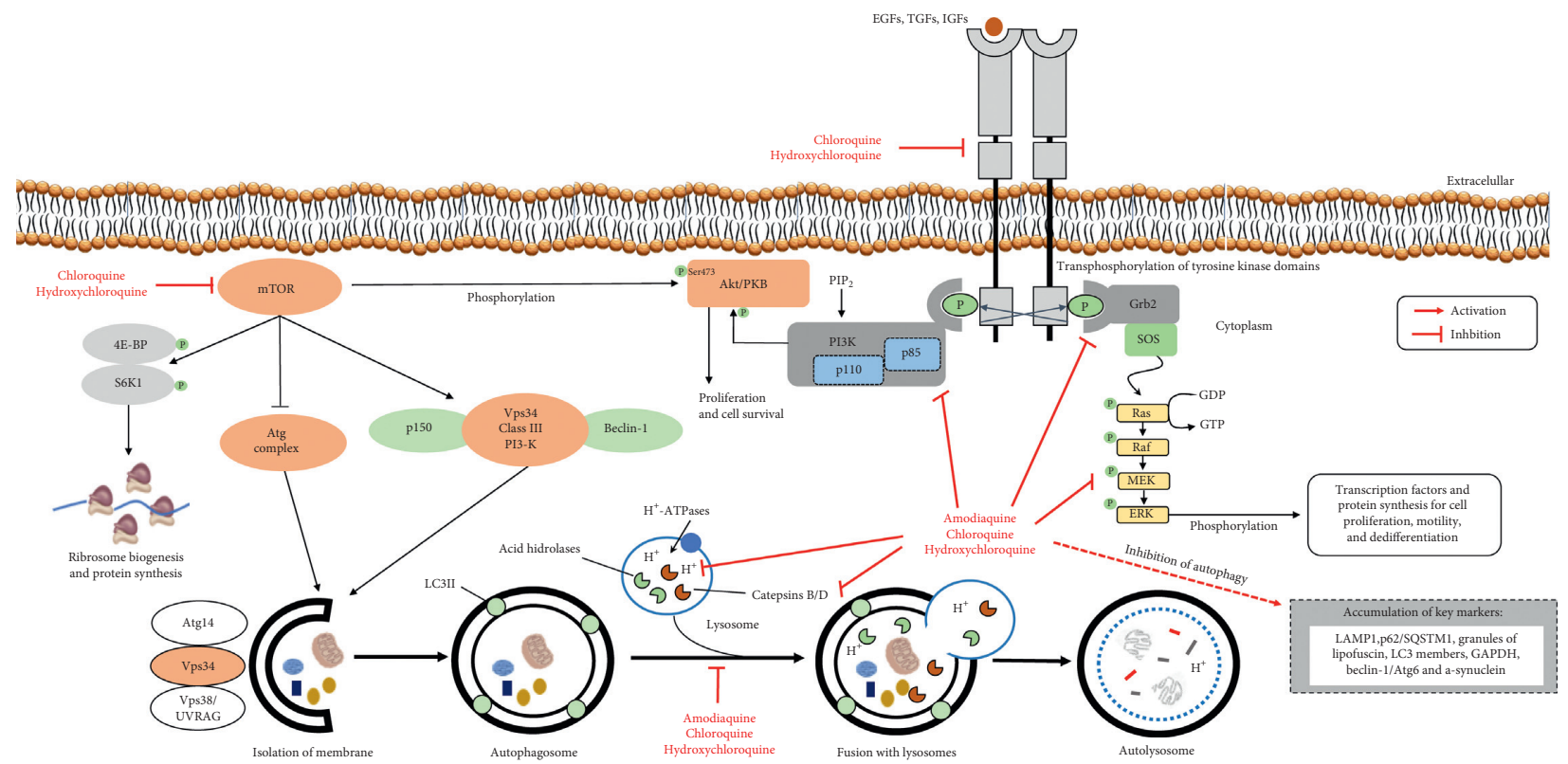

FIgUre 3: Molecular findings, which support the theory that chloroquine and analogues exerts, at least in part, antineoplastic effects altering the phosphorylation status of EGFR/PI3K/Akt/mTOR/Atg and p53 pathways, inhibiting directly PI3K-Akt and mTOR kinases, obstructing catalytic subunits in the ATP-binding site or altering the recycling of tyrosine kinase receptors, besides impairing or interfering in lysosomal and autophagosome functions. mTOR phosphorylates the eukaryotic initiation factor 4E-binding protein (4E-BP) and the p70S6 kinase 1 (S6K1). Therefore, if specific drug inhibitors against mTOR kinase are used, this should not only have altered proliferation but also the protein synthesis rate. Vesicular protein sorting 34 (Vps34) complex I has Atg14p as an additional factor, which participates in the formation of autophagosomes, while complex II has Vps38, which is required for vacuolar protein sorting. These catalytic complexes work as ubiquitin-like conjugation systems for phagophore elongation and recruitment of other proteins to the self-digesting process, as seen with Vps34, a phosphatidylinositol serine-threonine kinase, its binding partner Beclin-1 (Atg6) and the protein kinase p150 in mammals (Vps15). Assembly of this complex is crucial for autophagy and it recruits other proteins to the phagophore assembly site (PAS). Therefore, the phagophore elongates into a cup-shaped structure and begins to engulf cellular material, sequestering the material in a doublemembraned autophagosome. Both chloroquine and hydroxychloroquine block autophagy in initial phases, causing accumulation of acidic vesicle cell markers and appear to deactivate upstream members of mitogen-activated protein kinase (MAPK) pathway, preventing phosphorylation and activation of extracellular signal-regulated kinases (ERK)1/2 by a paradoxical phosphorylation of Raf at specific residues, which possibly blocks ERK activation by Akt activity.

microvessel density, and nitric oxide levels in colorectal cancers $[58,59]$. The growth of HT-29 colon cancer xenografts in bevacizumab- and oxaliplatin-treated mice was postponed from 7.2 to 23 days when bevacizumab and oxaliplatin were coadministered with chloroquine [58].

In addition to acting as inhibitors of autophagy, chloroquine, quinacrine, and amodiaquine trigger p53 stabilization in TP53-specific reporter human cancer cells [59] and wild-type cell lines [49, 72] (Figure 2). Amodiaquine in vitro at $20 \mu \mathrm{M}$ was specifically more efficient than chloroquine in inducing p53 stabilization by an independent ATM signaling pathway, interrupting cell proliferation of colorectal carcinoma cell lines (in addition to breast, hepatic, lung, sarcoma, and melanoma), decreasing the synthesis of a general ribosome precursor-47S rRNA-in U2OS cells, inducing the accumulation of LC3II autophagosome and lysosomal associated membrane protein 1 (LAMP1), and impairing translocation of the DDX21 nucleolar helicase to the nucleoplasma [49], the catalytic protein involved in the synthesis and processing of rRNA [73].

The nucleolar changes induced by amodiaquine were similar to those observed in cells treated with chloroquine and BMH-21l, a polymerase I inhibitor. Furthermore, amodiaquine inhibited the activity of ubiquitin ligase Hdm2's and thereby stabilized/activated p53 [49].

2.2.4. Breast Carcinomas. Quinidine [74-76], quinine [77], chloroquine [76, 77], and hydroxychloroquine [75] induced differentiation in MCF-7 cancer cells, as demonstrated by the accumulation of cells in the $G_{0}$ phase, intracellular milk fat globule membrane protein and lipid droplets (typical markers of differentiation), increased p21 and suppressed phosphorylation of retinoblastoma and expression of Ki-67 antigen, cyclin D1, c-myc, and E2F1 protein levels (Figure 2). While chloroquine was stronger in stimulating MCF-7 apoptosis, quinine was the most active in promoting differentiation [77].

Chloroquine or hydroxychloroquine + all-trans retinoic acid also reduced MCF-7 cells positive for Ki67, and their clonogenicity and hydroxychloroquine altered the acetylation status in the $\mathrm{N}$-terminal lysines of the histones $\mathrm{H} 3$ and H4, epigenetic sites expected by the "zip": model of histone acetylation [51]. These observations indicate that, in association with all-trans retinoic acid, quinidine, quinine, chloroquine, or hydroxychloroquine regulates protein 
acetylation events and the combination with all-trans retinoic acid stimulates histone acetyltransferase and inhibits HDAC enzymes in breast cancers (Figure 2). Nevertheless, the direct inhibition of the HDAC enzyme does not appear to be necessary for the differentiating activity of antimalarial quinolines [76].

Breast MCF-7 cells (wild-type for $\mathrm{p} 53$ ) presented $74 \%$ of cell cycle arrest in the $\mathrm{G}_{1}$ phase after $24 \mathrm{~h}$ and $72 \mathrm{~h}$ of exposure to chloroquine $50 \mu \mathrm{M}$ and everolimus [ $20 \mathrm{nM}, 40-O$ (2-hydroxyethyl)-rapamycin, an mTOR inhibitor], showing additive inhibitory effects when both drugs were added in 3$\mathrm{D}$ cocultures. This proliferative reduction was confirmed by DNA quantification and increased levels of p 53 and p21 ${ }^{\text {Cip1 }}$ after the treatment of MCF-7 cells with chloroquine, but not everolimus, which indicates that $G_{1}$ arrest is mediated by tumor suppressor pathways p53 and p21 [48].

Loehberg et al. [46] detailed the dependency of p53 on the effects of chloroquine on $\mathrm{BALB} / \mathrm{c}$ p53-null mammary epithelium cells and human mammary gland epithelial MCF10A line. Chloroquine-dependent DNA damage activates $\mathrm{p} 53$ and its downstream gene p21, resulting in the $\mathrm{G}_{1}$ cell cycle arrest after a post-translation p53 activation by chloroquine-induced phosphorylation of ATM proteins, proving the existence of ATM-dependent phosphorylation of the p53 checkpoint (Figure 2). These molecular findings may explain the particular ability of chloroquine $3.5 \mathrm{mg} / \mathrm{kg}$ to reduce the growth rate and tumor incidence by $41 \%$ only in p53-wild-type $\mathrm{BALB} / \mathrm{c}$ mice exposed to $\mathrm{N}$-methyl- $\mathrm{N}$ nitrosourea after 8 weeks of treatment. Since the TP53 is a mediator of hormone (estrogen/progesterone)-induced protection against chemical mammary carcinogenesis and no protection was observed in BALB/c p53-null mammary epithelium, it certainly shows that chloroquine can prevent breast cancer similar to estrogen/progesterone treatment and shows a p53 dependence [46].

As described before, autophagy is required for efficient growth of cells, and upon starvation chloroquine decreases LC3II lysosomal degradation [66, 73, 78, 79]. Therefore, 67-NR and 4-T1 mouse breast cell lines treated with chloroquine were sensitized preferentially in response to phosphoinositide 3-kinases or mTOR inhibitors, the route that directly regulates autophagy (Figure 3). Surprisingly, chloroquine sensitized 4-T1 and 67-NR cells to inhibit phosphoinositide 3-kinases or rapamycin even in Atg12 gene nonfunctional cells, and the pancaspase inhibitor zVAD-fmk (zVAD) did not increase cell survival, indicating that chloroquine should be able to sensitize even when autophagy has already been previously obstructed. Corroborating these findings, decreasing the cell viability involves a caspase-independent mechanism in which chloroquine but not bafilomycin A1 sensitizes cells to rapamycin-mediated cytotoxic actions, even though both of them block autophagy and LC3-II degradation [53].

2.2.5. Lung Cancers. Low concentrations of chloroquine $(0.25-32 \mu \mathrm{M})$ up to $24 \mathrm{~h}$ exposure induced apoptosis of adenocarcinoma lung A-549 cells and vacuolation with increased volume of acidic compartments, but caused necrosis at $48 \mathrm{~h}$ and higher concentrations, as demonstrated by lactate dehydrogenase assays. Interestingly, in the presence of D609, a specific inhibitor of phosphatidylcholine-specific phospholipase $C$, only lower concentration effects were suppressed [80].

$\mathrm{Hu}$ et al. [50], using screening cytotoxic methods and absorbance assays, pointed out that the coculture of chloroquine and Akt inhibitors (phosphatidylinositol analogs, oligopeptides Akt-PH linkers, direct inhibitors of Akt-kinase activity, and blockers of catalytic subunit in the ATP-binding site) are more effective than either one alone. Such killing effects of chloroquine-mediated chemosensitization occurs at low concentrations as $10-20 \mu \mathrm{M}$ and present specificity up to 120 -fold for killing cancer than normal cells [50]. These findings indicate that chloroquine might significantly increase the therapeutic effects of some PI3K-Akt inhibitors with minor action on immortalized normal mammary gland epithelium 184B5 cells. Probably, chloroquine-mediated chemosensitization is related to the ability to block the formation of digestive vesicles, as those activated by tephrosin on cells, a natural rotenoid that induces endocytosis and subsequent degradation of human epithelial tyrosine kinase (HER-1 and 2) receptors [81].

2.2.6. Melanomas. A screening chemical library of antimalarial drugs against melanomas showed the endoperoxide-based redox antimalarial artemisinin-class members as inducers of apoptosis, while metastatic melanoma cells (A375, G361, and LOX) displayed a specific vulnerability to artemisinin and semisynthetic artemisinin-derivatives and NOXA-dependent apoptosis [82], a proapoptotic member of the Bcl2 family. Such sensitivity was corroborated by the upregulation of cellular oxidative stress, phosphatidylserine externalization, and cleavage of procaspase-3 [82]. Next, amodiaquine-exposed A-375 and G361 melanoma cells exhibited the formation of multivesicular single membraneenclosed structures with electron-dense inclusions (indicative of lysosomal expansion), impairment of mitochondrial transmembrane potential, and accumulation of LAMP1, p62/SQSTM1, $\alpha$-synuclein, lipofuscin, and LC3-II at concentrations as low as $1 \mu \mathrm{M}$ [57], all accumulating autophagic proteins as a consequence of blocked autophagic-lysosomal flux (Figure 3). Such a blockade revealed a similar pattern of impaired lysosomal acidification in response to the treatment with either bafilomycin A1, amodiaquine, and chloroquine from a mechanistic point of view.

Intriguingly, a comparative analysis performed in A375 melanoma cells showed higher antiproliferative activity of amodiaquine when compared to chloroquine, which was confirmed by array analysis, revealing the modulation of gene expression antagonizing cell cycle progression (upregulation of CDKN1A and downregulation of E2F1) and modulation of the genes TP53, CDKN1A, E2F1, CCND1, and phosphorylated RB1. On the other hand, chloroquine failed to alter protein levels of TP53, E2F1, CCND1, and HSPA1A in A375 cells, demonstrating that the chloroquine treatment was not associated with the induction of cell cycle arrest, a finding extremely different from amodiaquine-induced melanoma cell cycle obstruction in the $S$ phase [57]. 
Previous studies had already indicated amodiaquine as a more potent antimalarial molecule than chloroquine, a property attributed to a tropism targeting the acidic food vacuole of the plasmodium parasite [83]. Amodiaquine is a lysosomotropic 4-aminoquinoline-based tertiary amine as well, but it has a 1,4-aminophenol-pharmacophoric substituent capable of forming an electrophilic quinoneiminemetabolite under intracellular conditions of oxidation. Then, this reactive intermediate induces covalent protein adductions [57] and may contribute to higher potency.

2.2.7. Retinal Pigment Epithelial Cells. $10-250 \mu \mathrm{M}$ chloroquine produced a persistent reduction in mTOR activity and intracellular calcium in retinal ARPE-19 cells, leading to the nuclear translocation of transcriptional factors for lysosomal biogenesis, expansion of lysosomes, severe suppression of autophagosome-lysosome fusion, and increased cytosolic levels of LAMP1, beclin-1, glyceraldehyde 3-phosphate dehydrogenase (GAPDH), and phospholipid intracellular content in 25-fold or greater [40,84].

The inhibitors of endocytosis reduce endosomes and arrest a considerable amount of GAPDH into lysosomal cytosolic vesicles and cell membranes. On the other hand, its degradation is physiologically reduced or blocked as an adaptive reaction of lysosomes to retrieve normal functions, although accumulation of intracellular substrates, including p62, GAPDH, and phospholipids, are not entirely reestablished [84]. Anyway, chloroquine-induced protein accumulation indicates autophagy inhibition because p62 and GAPDH are degraded by lysosomes via autophagy and chaperon-mediated autophagy pathways, respectively [85].

GAPDH, an enzymatic $144-\mathrm{kDa}$ tetramer expressed on the cell surface and secreted from cells leading to forward trafficking of active GAPDH out of cells, actively contributes to endosomal recruitment [85]. The versatility and promiscuity of functions and its interaction with multiple protein partners make GAPDH a vital tool for cell survival because it works as a scavenger agent to flush out misfolded molecules and activates inside processes during membrane trafficking and production of secretory lysosomes [86].

2.2.8. Mouse Embryonic Fibroblasts. In mouse embryonic fibroblasts (MEF), chloroquine and hydroxychloroquine confirmed their capacity to block autophagy in a concentrationdependent manner [87]. Indeed, $\mathrm{Bax}^{-/-}$and $\mathrm{Bak}^{-/-} \mathrm{MEF}$ cells were resistant against hydroxychloroquine-induced mitochondrial and plasma membrane permeabilization and hydroxychloroquine induced cathepsin B intracellular redistribution (Figure 3); besides, it was unable to cause mitochondrial depolarization, release of cytochrome $c$, or cell death when compared to wild-type MEF cells. Altogether, these data imply a specific sequence of subcellular alterations: (a) lysosomal accumulation resulting in the selective loss of mitochondrial potential and release of lysosomal enzymes, such as cathepsin B; (b) activation of Bax and mitochondrial permeabilization, and (c) caspase-3 activation, phosphatidylserine exposure, chromatin condensation, DNA loss, and apoptosis (Figure 2) [36]. Correspondingly, in vivo effects following $24 \mathrm{~h}$ or $48 \mathrm{~h}$ exposure of C57BL/6JOlaHsd mice to hydroxychloroquine $60 \mathrm{mg} / \mathrm{kg}$ showed Golgi changes and accumulation of LC3 [87].

These cells were also tested with a panel of approvedFDA drugs containing either quinoline or quinolone pharmacophores. Chloroquine caused the secretion of prostate apoptosis response-4 (Par-4) from wild-type p53 MEFs (Figure 2), as well as from normal human prostate stromal and lung fibroblast cells and their respective aminoquinoline derivatives, and induced Par-4 systemic secretion in C57BL/ 6 mice in a dose of $50 \mathrm{mg} / \mathrm{kg}$ body weight, and in patients from a clinical trial against cancer prior to surgery taking hydroxychloroquine [88]. As predictable, chloroquine caused the accumulation of LC-3II and p62/ SQSTM1, but drug-induced secretion of Par-4 was not inhibited by zVAD, and differences in p62 levels have not been noticed after the treatment with wild-type Par-4 and Par- $4^{-1-}$ cells [88].

Par-4 is a tumor suppressor capable of inducing apoptosis selectively in most cancer cells without affecting normal/immortalized/nontransformed ones. The increase of Par-4 in the extracellular matrix causes cell death of tumor cells through binding to the overexpressing GRP78 receptor on the cell surface. Normal lines exhibit undetectable-to-low levels of this receptor [89], which protect them from the "friendly fire" though Par-4 is secreted by both normal and cancer tissues [89, 90]. Therefore, Par-4 secretion is not associated with apoptosis and does not affect autophagy in normal mouse embryonic fibroblasts. Meanwhile, the cocultures of chloroquine-treated $\mathrm{Par}-4^{+/+} \mathrm{MEFs}$ plus $\mathrm{H}-460$ lung $\mathrm{p}^{+/+}$and $\mathrm{H}-1299$, HOP92, and $\mathrm{KP}-7 \mathrm{~B}$ lung or prostate $\mathrm{PC}-3 \mathrm{p} 53^{-/-}$cancer cells were sensitive to apoptosis, but not when cocultured with chloroquine-treated Par- $4^{-/-}$ MEFs, and chloroquine failed to induce Par-4 secretion in prostate cancer cells (LNCaP, C42B, DU-145, and PC-3) and lung cancer cells (H-460 and A-549). These discoveries indicate that chloroquine-induced Par-4 secretion from normal lines causes paracrine apoptosis in cancer cells [86], and such action increases the selective expression of Par-4 receptor GRP78 on the surface of cancer cells [91] (Figure 2).

In vivo related findings in C57BL/ 6 mice bearing LLC1 pulmonary tumors also showed systemic elevation of Par-4 regressed tumor growth and metastatic lung nodules in animals treated with chloroquine $25 \mathrm{mg} / \mathrm{kg} /$ days for 5 consecutive days $[88,90]$. Once again, the antiproliferative activity of chloroquine is linked to the activation of p53 and inhibition of NF $-\kappa \mathrm{B}$ because these events promote Par- 4 secretion [88] because p53 regulates classical components of the secretory route (Figure 2). This relatively unknown $\mathrm{Par}-4$ pathway adds new importance to the traditional DNA protection roles of normal TP53 gene to manage the tumor suppressor.

\subsection{We Need to Think Outside the Box}

2.3.1. New Pharmacological Judgement. Traditional comprehension about the effects of chloroquine and analogues on the lysosomal physiology implies a specific sequence of subcellular alterations: (a) lysosomal accumulation resulting in the selective release of lysosomal enzymes, such as 
cathepsin B and D; (b) activation of Bax/Bad and mitochondrial permeabilization; (c) loss of mitochondrial potential, and (d) activation of caspases, phosphatidylserine exposure, chromatin condensation, DNA loss, and apoptosis (Figure 2).

However, new pharmacological judgements have arisen and changed some scientific dogmas in this area. Higher lysosomal $\mathrm{pH}$ was observed after $4 \mathrm{~h}$ of treatment with known alkalinizer drugs (fluoxetine, imipramine, dimebon, tamoxifen, chlorpromazine, amitriptyline, and verapamil), including chloroquine. Considering their high lipophilic structures (clogP ranging from 3.49 to 6.24 ), this suggests suitable entry into target cells including osteosarcoma U2OS, adenocarcinoma cervical HeLa, embryonic rat cardiomyocytes $\mathrm{H} 9 \mathrm{C} 2$, and the human retinal pigment epithelial ARPE-19 line. Indeed, among amodiaquine, artemisinin, mefloquine, piperaquine, primaquine, quinacrine, and chloroquine, two antimalarial compounds (mefloquine and quinacrine) were about 30- and 60-fold more potent autophagy inhibitors on U2OS cells than chloroquine, respectively [92].

However, higher $\mathrm{pH}$ values were sustained no more than the compound exposure time, and after $24 \mathrm{~h}$, renewed acidic organelles with $\mathrm{pH}$ between 4-5 were detected, indicating restorage of $\mathrm{pH}$, which was also confirmed by nuclear translocation of transcription factors involved in lysosomal biogenesis, bigger lysosomal volume, and returning of cathepsin levels in order to reestablish optimal conditions for enzyme digestion [84, 93, 94].

Most studies have also suggested that chloroquine- or hydroxychloroquine-induced cell death is initiated by the "type II programmed autophagic/lysosomal pathway," including sequestration of organelles into autophagosomes and cytoplasmic vacuolization (Figure 3), and these processes are followed by later signs of the "type I programmed death" $[36,40,66]$, which traditionally display karyorrhexis, DNA fragmentation, release of mitochondrial cytochrome $c$, activation of $\mathrm{Bcl}-2$ proapoptotic proteins and caspases, cellular shrinkage, and phosphatidylserine externalization (Figure 2). Additionally, although members of the 4-aminoquinoline family, including chloroquine, hydroxychloroquine, and Lys-05 (dimeric chloroquine) inhibit autophagy [68], it has been suggested that ribosome biogenesis stress found in treated cells is not a general consequence of autophagy inhibition and that amodiaquine stands out among the 4-aminoquinoline family as a compound functioning by 2 independent mechanisms in two distinct intracellular environments: cytoplasm, where autophagy inhibition occurs and nucleolus, for diminution/ blockage of ribosome biogenesis [49], which demonstrate that amodiaquine but not chloroquine inhibits ribosome biogenesis, disrupts nucleolar structure, and triggers degradation of RNA polymerase I.

As endosomal trafficking, endosome-lysosome fusion, membrane stability, signaling pathways, and transcriptional activity are impaired by hydroxychloroquine and chloroquine, it was hypothesized that combining them with radiation would be a good adjuvant alternative [47]. Nevertheless, chloroquine sensitization of some breast cancer lines revealed to be independent of autophagy inhibition, since sensitization was not mimicked by the knockdown of Atg12 or Beclin 1 genes or following treatment with bafilomycin $\mathrm{A} 1$, and chloroquine-induced cell death occurred even in the absence of Atg12 [53], proposing that reducing autophagy does not affect drug cytotoxicity ubiquitously in all human cells. Meanwhile, studies have demonstrated that chloroquine has specific cell sensitization effects to particular antimitotic drugs, whereas primaquine and mefloquine can sensitize resistant cancer cells to all antimitotic drugs without preference [81].

In a similar way, most investigations indicate that chloroquine does not block all forms and steps of the endolysosomal system. Analysis showed that chloroquine/ hydroxychloroquine inhibits autophagy in initial phases, causing accumulation of acidic vesicular organelles and break/discontinue autophagosome-lysosome fusions, but they do not alter the ability of lysosomes to digest target macromolecules as conventionally accepted. In another point of view, compounds that simply increase the upstream autophagic flux without altering downstream fusion and degradation steps may not provide therapeutic benefit [95]. This would explain why only chloroquine and hydroxychloroquine are officially recommended as autophagy inhibitors by the Food and Drug Administration (FDA).

If we recall a more integrated concept, considering the well-established details about the blockage of autophagic flux and the capacity to inhibit PI3K/Akt/mTOR pathways and trigger ATM/ATR/p53/p21 signaling, it is possible to visualize that they complement themselves to cause death of cancer cells. Once mTOR is commonly phosphorylated at position 2448 via the PI3K/Akt and has been inhibited when higher levels of p15 $5^{\mathrm{INK} 4 \mathrm{~B}}, \mathrm{p} 16^{\mathrm{INK} 4 \mathrm{~A}}, \mathrm{p} 21^{\mathrm{Cip} 1}, \mathrm{p} 27^{\mathrm{Kip} 1}, \mathrm{p} 53$, and other suppressor tumors are present under stress conditions, p21 obliges $G_{1}$ restriction by inhibitory binding to $\mathrm{CDK} 2 /$ cyclin $\mathrm{E}$ or other $\mathrm{CDK} /$ cyclin complexes [45]. These physiological aspects support the theory that chloroquine or hydroxychloroquine exhibits, at least in part, antineoplastic effects altering the phosphorylation status of EGFR/PI3K/Akt/mTOR/Atg and p53 pathways $[43,46,48,49,57]$ due to the direct inhibition of PI3K-Akt kinases, obstruction of catalytic subunits in the ATP-binding site [80], and/or misregulation of signaling of epithelial growth factor receptors (EGFRs) during endocytosis because they seem to weaken receptor-mediated endocytic transfers of TKRs to degradative compartments [95] (Figure 3).

In this context, the inhibition of tyrosine kinase receptors and downstream pathways (Receptor/PI3K/Akt or Receptor/Grb2/Ras/Raf/MEK/ERK) are examples of suitable targets to select antitumor repurposing molecules [50, 80, 81] (Figure 3). Despite that tyrosine kinase inhibitors have demonstrated enhanced selectivity, extra effects on some kinases and beyond their target family show intrinsic polypharmacology often favorable for clinical efficacy [6]. Therefore, blocking the signaling pathways that maintain the stemness is thus a rational goal to avoid recurrence as well as to block tumor growth and metastasis. Metastatic cancer or surgically nonresectable tumors show five years mortality above $90 \%$ in aggressive cancers, e.g., pancreatic tumors and 
acute myeloid leukemia. Hence, with a few exceptions, survival rates of aggressive cancer types are low, mainly due to therapeutic failure [15].

Instinctively, these new studies indicate that chloroquine does not increase lysosomal alkalinization in all cell types in a similar magnitude, and lysosomes may even maintain their competence (completely or not) to digest organic material, confirming that chloroquine inhibits the fusion between autophagosomes and lysosomes in a concentration-dependent way, but it does not change the lysosomal activity considerably $[84,87]$. The extent of increase in lysosomal pH and how much time lysosomes demand to normalize after compound exposure can diverge a lot if we take into consideration cell specificities, doubling time, phagocyte capacity, and how efficiently the cells/lysosomes respond to the compound sequestration. In a cell point of view, autophagy responses constitute stress adaptation that can suppress apoptosis, but when autophagy is blocked either at earlier or later stages, it may lead to apoptosis as a result of the failure for adaptation to environmental changed states.

Overall, the precise mechanism by which quinines sensitizes cancer cells by PI3K-Akt or MEK/ERK inhibitors is unclear, but it is recognized that such signal pathways are overexpressed or upregulated in cancer rather than in normal cells, which opens a "window of opportunities" to design more target drugs and clinical trials based on the lysosomal blockade ability. It is very important to remember that patients with metastases present tumors with multiple molecular and cellular characteristics. Therefore, the heterogeneity of metastases, tumor advance, and cell selection becomes a common problem observed in tumor resistance during the first line chemotherapies [6]. Therefore, including sensitizers with antimutagenic action (such as chloroquine) reduces the extent of primary DNA rearrangements responsible for the appearance of mutant clones and may delay/inhibit tumor progression.

A generalized overview also emphasizes the most vulnerable issue: do the effects of aminoquinolines share a common mode of action or are they the products of a variety of distinct processes? Once their mechanisms remain uncertain, molecular and clinical lessons are indispensable to detail dose/concentration-response relationships and safetyrelated aspects to guide the development of new modulating autophagy therapies [30].

2.3.2. Pharmacokinetic-Related Toxicity. The most common adverse effects of chloroquine, hydroxychloroquine, amodiaquine, and other aminoquinolines in clinical use are nausea, abdominal/hypochondrial pain, changes in visual acuity (blurred vision), bitter taste in mouth, insomnia, weakness, arthralgia, back pain, pruritus (sensation of itching and stinging), diarrhea, and pale stools. Indeed, up to $50 \%$ of patients receiving hydroxychloroquine report some gastrointestinal effects. This is dose-dependent and most often occurs with loading doses $>800 \mathrm{mg}[96,97]$, but $400-800 \mathrm{mg}$ daily doses have been related to symptoms of psychosis, agitation, insomnia, confusion, hallucinations, paranoia, depression, catatonia, and suicides. These psychological/neurological effects may appear at any age, during acute or chronic use, and in patients with or without a history of psychiatric illness [98].

Poisoning with antimalarial drugs have also caused cardiovascular problems such as myocarditis, ventricular arrhythmias, cardiac arrest, and QTc prolongation due to the blockade of hERG potassium channels. Thereof, chloroquine, hydroxychloroquine, amodiaquine, and other derivatives should be used with caution in oncologic patients with cardiac diseases, history of ventricular arrhythmias, hypokalemia and/or hypomagnesemia, or bradycardia ('50 bpm), and during concomitant administration of QT interval prolonging agents (e.g., macrolides and fluoroquinolones) [9, 99-101]. If cardiotoxicity is suspected, quick discontinuation of the QT interval prolonging agents may prevent life-threatening complications.

Severe hypoglycemia with the loss of consciousness in patients treated or not with antidiabetic medications have been observed [102], inspite of beneficial effects for the metabolic syndrome [103]. Therefore, patients presenting clinical symptoms of hypoglycemia during treatment should have their blood glucose checked and treatment reviewed when necessary. Additionally, rhabdomyolysis [99] and ototoxicity when they are used by pregnant women in the 3rd trimester and even irreversible deafness [104] were reported. Nonetheless, health guidelines have indicated the maintenance of treatment with hydroxychloroquine during pregnancy and breastfeeding in patients with autoimmune diseases since these aminoquinolines do not cross the placenta easily and low quantity is found in breast milk [105].

Chloroquine and hydroxychloroquine structures and modes of action are closely similar except for an additional hydroxyl moiety, which makes hydroxychloroquine less permeable to blood-retinal barrier, and it allows faster clearance from retinal pigment cell, suggesting minor risks and safer option since long-term clinical trials with hydroxychloroquine tolerates higher daily doses and revealed less drug-drug interactions [102]. Their therapeutic window is relatively narrow, and retinal damage is one of the most common side effects for long term use [106]. Around $20 \%$ of chloroquine users showed ocular injuries due to high doses and treatment frequency in 1980s [39], and, since 1974 , it has been a prescribed medicine in Japan due to chloroquine-associated retinopathy [107]. Thus, ocular or color vision examinations of patients under antimalarial therapies is indispensable for the early detection of retinal toxicity at a stage in which it is still reversible once treatment is interrupted [39]. The initial development of retinal damages with a daily dose of 800 to $1200 \mathrm{mg}$ of hydroxychloroquine has been detected using sensitive retinal screening tests [108].

The simultaneous use of tamoxifen-the most prescribed selective modulator of estrogen receptors to treat hormonereceptor-positive, early/advanced-stage or metastatic breast cancers after surgery to reduce the risk of recurring-with hydroxychloroquine increases the risk of eye toxicity owing to the synergistic block of lysosomal/autophagy steps in retinal epithelial cells and accumulation of potentially toxic ubiquitinated proteins [108]. Although retinopathy is more 


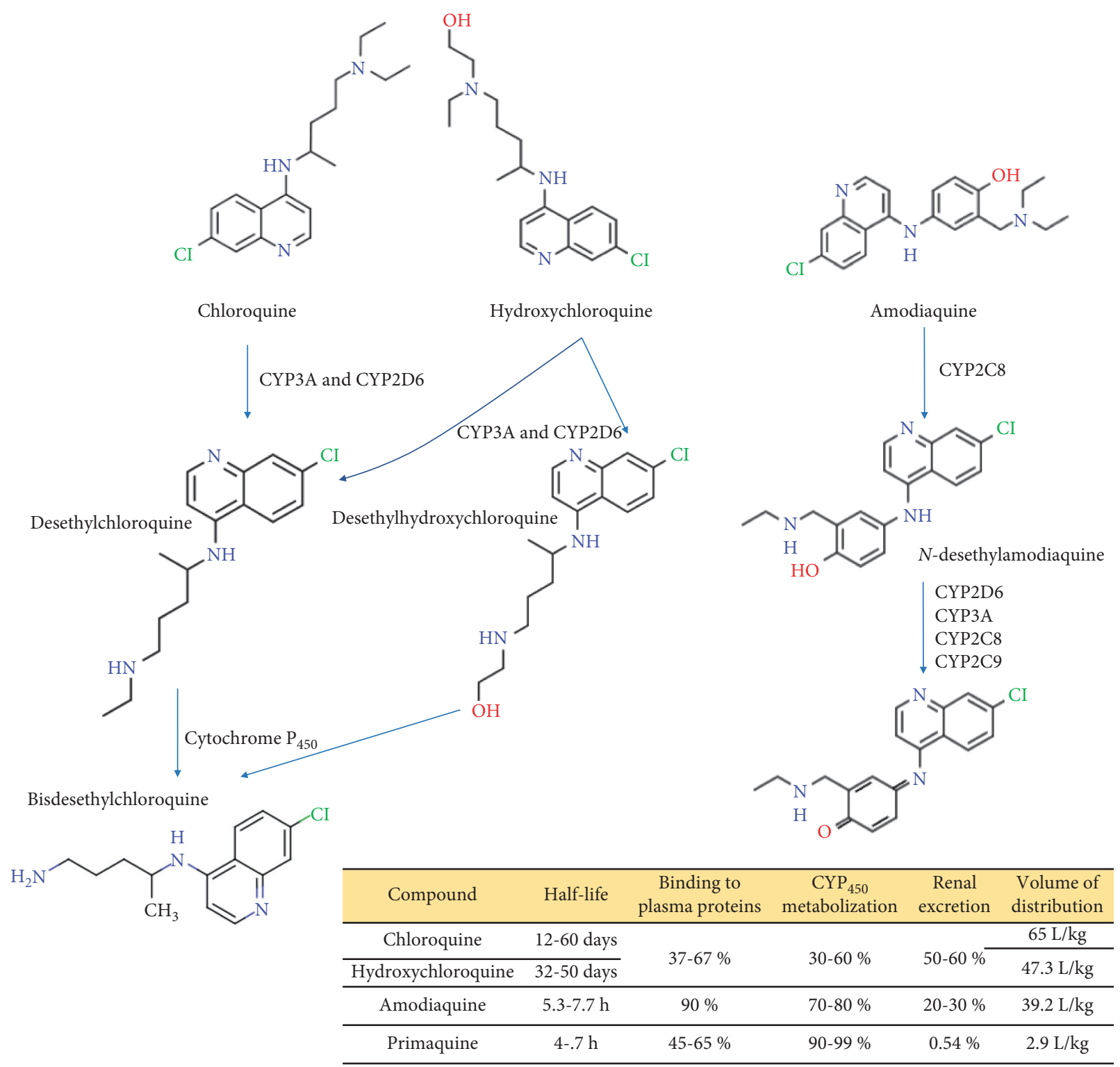

Figure 4: Metabolism of some aminoquinolines and pharmacokinetic features.

commonly correlated with chloroquine than with hydroxychloroquine, which might also be explained by the lower volume of distribution (Vd) for hydroxychloroquine (47.3 L) compared with chloroquine (65L) (Figure 4). Ophthalmology guidelines have recommended comedication of tamoxifen plus hydroxychloroquine for up to 6 months, and a maximal daily dose of $5 \mathrm{mg} / \mathrm{kg} /$ day body weight of hydroxychloroquine not more than 5 years [30, 40, 106, 109].

Besides molecular similarities, chloroquine and hydroxychloroquine occur as enantiomers ( $\mathrm{R}$ and $\mathrm{S}$ isomers), and in vitro and in vivo analyses have not shown important differences owing to the bioactivity [30], stereoselectivity of drug-drug interactions, and clinical consequences on toxicity due to the preferential metabolism of one enantiomer [105]. Both $S(+)$-chloroquine and -hydroxychloroquine present higher binding to albumin and $\alpha_{1}$-acid glycoprotein, but hydroxychloroquine was enantioselective in vivo and in healthy volunteers, indicating the less protein-bound $\mathrm{R}(-)$-enantiomer [110]. Then, the hydroxychloroquine binding degree to plasma proteins seems to control its distribution into cells, which can help explain how chloroquine have a larger $\mathrm{Vd}$, since its $\mathrm{R}(-)$ enantiomer is almost 2 -fold less protein bound than the $\mathrm{S}(+)$-enantiomer [105]. Notably, the $\mathrm{S}(+)$-form of hydroxychloroquine is less taken up by rabbit ocular tissues [111], which suggests that the administration of the pure $S(+)$ enantiomer could offer better efficacy and lesser toxicity [105].

Experimental blockers such as 3-MA, bafilomycin A1, and short hairpin RNA (shRNA) knockdown of gene Beclin cause the deficiency of autophagy and increase tubular cell p53-dependent apoptosis during cisplatin treatment in kidney proximal tubular cells [112], supporting convincing 


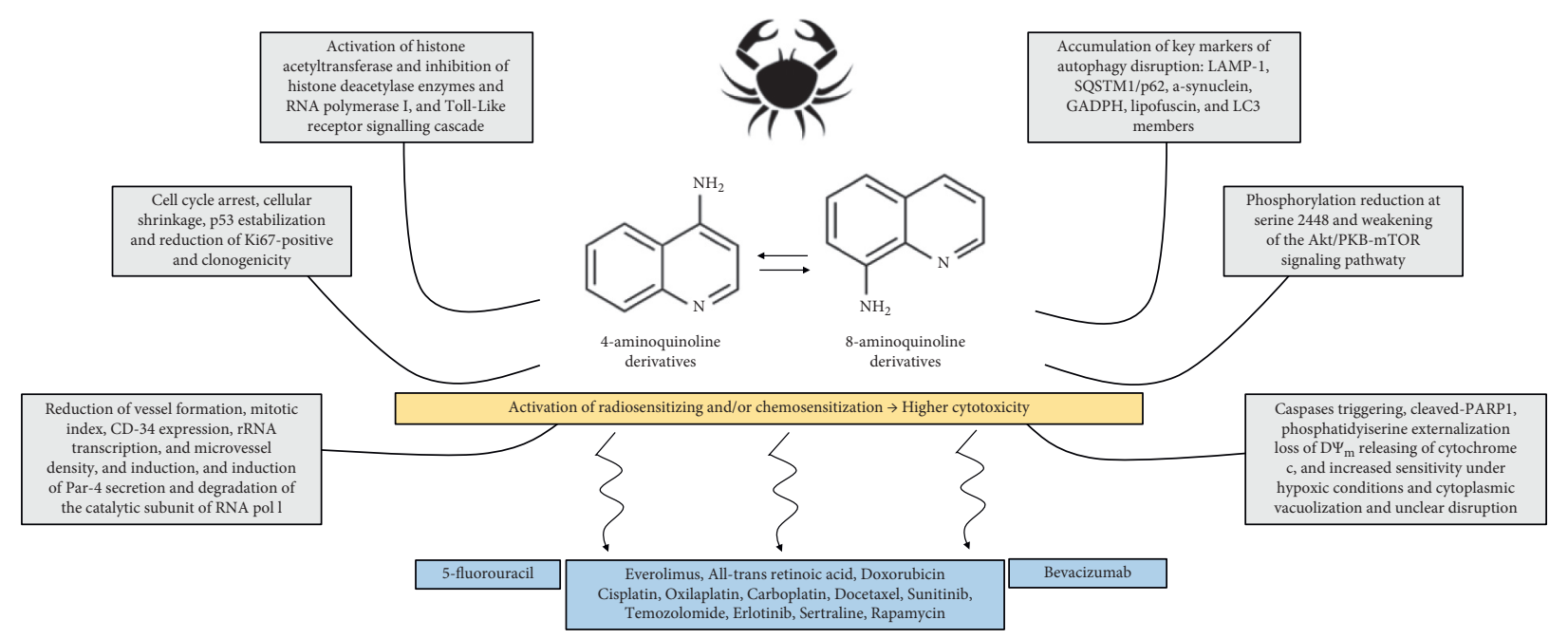

FIgURE 5: General properties of aminoquinolines on tumors.

data that autophagy is critical for renal cell survival. Hence, the concomitant exposure to anticancer agents and clinically available autophagy blockers (e.g., amodiaquine, primaquine, and analogues) also sensitizes normal tissues and can dramatically worsen renal function in patients with acute or chronic kidney illnesses. Under these circumstances, an impaired renal function increases the bioavailability of antimalarial drugs and comedications and the risk of adverse effects by pharmacological interactions.

In the pharmacokinetic context: (i) a single oral dose of chloroquine $300 \mathrm{mg}$ can be detected in blood and urine from healthy volunteers up to 52 and 119 days postdose, respectively [113]; (ii) terminal elimination half-life of chloroquine, hydroxychloroquine, and their active metabolites (desethylchloroquine and desethylhydroxychloroquine, respectively, and finally, bisdesethyl chloroquine as a downstream metabolite of both drugs) varies from 20-60 days $[30,114]$; (iii) both drugs can distribute to aqueous cellular and intercellular compartments, resulting in long mean residence times (about 1,300 h for hydroxychloroquine and $900 \mathrm{~h}$ for chloroquine) [114]; (iv) 30 to $50 \%$ of these antimalarial drugs are transformed by hepatic cytochromes $\mathrm{P}_{450}$, mainly, CYP3A and CYP2D6 [115], and (v) about 37-67\% of chloroquine/hydroxychloroquine bound to liver-derived plasma proteins $[110,116,117]$. Additionally, the half-life of amodiaquine is only $5.3-7.7 \mathrm{~h}$, since it is subject to rapid first-pass metabolism and generate $N$-desethylamodiaquine, the principal route of disposition in humans, whose active metabolite has half-life $>100 \mathrm{~h}$ and, therefore, amodiaquine can be considered a prodrug [118]. Thus, in contrast to amodiaquine, chloroquine and hydroxychloroquine are not highly bound to plasma proteins but have strong tissue binding.

It is also critical to ponder the coexistence of hepatic diseases (cancer-related or not), first pass metabolism, and comedications if the question is bioavailability or linked-side effects because elimination is significantly reduced in the presence of hepatic dysfunction, and nearly $50 \%$ of chloroquine is recovered in urine as unchanged drug. As background, a recent Brazilian study showed that the administration of hydroxychloroquine (400 $\mathrm{mg}$ twice daily for 7 days) without or with azithromycin (500 mg once a day for 7 days) caused a rise in liver-enzyme levels [119].

Indeed, clinical trials with anticancer purposes showed that adverse effects and toxicity of chloroquine and hydroxychloroquine are strongly dose-dependent (100-1200 mg/day). According to Common Terminology Criteria for Adverse Events version 3.0, toxicity was found with 100 to $200 \mathrm{mg} /$ day [120-122]. Between 200 and $600 \mathrm{mg} /$ day, the most common adverse effects were classified as grade 1 and 2, and include rash, visual blurring, sensitivity to light, nausea, diarrhea, fatigue, weight loss, vomiting, dyspepsia, anorexia, and dry skin [123-128]. The adverse effects of grade 3 or higher were detected from 600 to $1200 \mathrm{mg} /$ day. Grade 4 toxicity was associated with myelosuppression at $800 \mathrm{mg} /$ day of hydroxychloroquine [122]. Meanwhile, the combination of temsirolimus ( $25 \mathrm{mg} / \mathrm{day}$, mTOR inhibitor) and hydroxychloroquine (200-1200 mg/day) was considered safe and tolerable, even at highest doses in patients with advanced solid tumors and melanoma [126]. Grade 2 or 3 adverse events were more common, resulting in a decrease of dosages after 2-3 months of treatment. Hydroxychloroquine and bortezomib, a proteasome inhibitor administered in patients with relapsed/refractory myeloma, cause grade 1 or 2 adverse events, mainly, but some patients experienced bone marrow suppression and grade 3 gastrointestinal toxicity [127]. At $1200 \mathrm{mg} /$ day, hydroxychloroquine induced lymphopenia and an increase in serum alanine aminotransferase (grade 3/4) in patients with metastatic pancreatic cancer [128].

\section{Conclusions}

The mechanisms of sensitization attributed to aminoquinolines have a histological basis, but most of them are interconnected to the autophagic process. They express signals of autophagy disruption and cytotoxic-related action, including accumulation of key markers, predominantly, 
LAMP1, p62/SQSTM1, LC3 members, GAPDH, beclin-1/ Atg6, $\alpha$-synuclein, and granules of lipofuscin.

Aminoquinolines act as lysosomal alkalinizers and take ownership during death-promoting mechanisms, which explain, at least in part, their chemotherapy and radiotherapy sensitizer effects when used as adjuvant option in clinical trials against solid tumors. They overturn lysosomalrelated pathophysiological barriers, reduces uptake and drug distribution, avoid resistance, and improve cytotoxic activity response of weak-base clinical drugs, since they work as chemosensitizers under specific microenvironmental conditions, especially when acid lysosomal and inflamed tissues $\mathrm{pH}$ cause ion trapping and sequestering of chemotherapeutic drugs into protonated acidic endosomes. Additionally, they have also overwhelmed tumor resistance in vivo, suggesting that autophagy inhibition has antiangiogenic effectiveness as well. Therefore, in a mechanistic point of view, aminoquinolines induce ATM-ATR/p53/p21 signaling, caspase activation, and exhibit unspecific capacity for overlapping the apoptotic cascade to either upstream of caspase-3 activation and/or encompass nonp53/apoptotic/ autophagy routes (Figure 5).

More specifically, two 4-aminoquinolines-chloroquine and hydroxychloroquine-accumulate slowly into cells and take time to develop cytotoxicity. Then, longer time exposure is believed to provide better antiproliferative effects, considering that they have a late onset but a prolonged action even after drug discontinuation. Moreover, no important differences have been found about the stereoselectivity of drug-drug interactions, clinical consequences on bioactivities, and additional pharmacokinetic-related toxicities. However, a continuous pharmacovigilance is required because these antimalarial molecules exhibit multiple cellular unspecific modes of action (undesired off-targets), relatively narrow therapeutic windows, recurrent adverse effects, and self-treatment-related poisoning. Retinopathy, mainly, has been more associated with chloroquine, and compromised renal and liver functions and increased the bioavailability of antimalarials and risk of adverse interactions. Therefore, their use must be under rigorous rules, ethical and medical prescription, and clinical and laboratory follow-ups.

\section{Abbreviations}

ATM- Ataxia telangiectasia-mutated/ataxia

ATR: $\quad$ telangiectasia and Rad3-related kinases

Atg: $\quad$ Autophagy-related protein

CDK: Cyclin-dependent kinase

EGFR: Epithelial growth factor receptor

GAPDH: Glyceraldehyde 3-phosphate dehydrogenase

GRP78: $\quad$ Glucose regulated protein 78

LAMP1: Lysosomal associated membrane protein 1

MAPK: Mitogen-activated protein kinases, originally

called ERK, extracellular signal-regulated kinases

LC3: Microtubule-associated protein 1A/1B-light

chain 3

NF- $\kappa$ B: $\quad$ Factor nuclear kappa B

Par-4: Prostate apoptosis response-4 p53: $\quad$ Protein 53

p62: $\quad$ Protein 62

PARP1: Poly-(ADP-ribose)-polymerase 1

PI3K: Phosphatidylinositol 3-kinases

SQSTM1: Sequestosome 1

S6K1: $\quad$ p70S6 kinase1

TLR: Toll-like receptor

TKR: Tyrosine kinase receptor

UACA: Uveal autoantigen with coiled-coil domains and ankyrin repeats

Vps34: Vesicular protein sorting 34

4E-BP: 4E-binding protein

5-FU: 5-Fluorouracil

zVAD- Benzyloxycarbonyl-Val-Ala-Asp-fluoromethyl

fmk: ketone.

\section{Data Availability}

The data used to support the findings of this study are cited as references.

\section{Conflicts of Interest}

The authors declare that they have no conflicts of financial interest or personal relationships that could influence this work and outcomes reported in this paper.

\section{Authors' Contributions}

PMPF planned the review and wrote about mechanisms of action and toxicokinetic findings. JROF collaborated in toxicity-related issues. DPB discussed about drug reuse with anticancer purposes. RWRS and GCGM analyzed in vitro mechanisms and revised the article. All authors have read and agreed to the published version of the manuscript.

\section{Acknowledgments}

Dr Paulo Michel Pinheiro Ferreira and Dr Daniel Pereira Bezerra are grateful to the public Brazilian agency "Conselho Nacional de Desenvolvimento Científico e Tecnológico" (CNPq) for their personal scholarships (303247/2019-3 and 313350/2018-3, respectively).

\section{References}

[1] M. Plummer, C. De Martel, J. Vignat, J. Ferlay, F. Bray, and S. Franceschi, "Global burden of cancers attributable to infections in 2012: a synthetic analysis," The Lancet Global Health, vol. 4, pp. e609-16, 2016.

[2] GBD Risk Factors Collaborators, "Global, regional, and national comparative risk assessment of 79 behavioural, environmental and occupational, and metabolic risks or clusters of risks, 1990-2015: a systematic analysis for the global burden of disease study 2015," The Lancet, vol. 388, pp. 1659-1724, 2016.

[3] World Health Organization (WHO), Cancer. Fact Sheet, World Health Organization, Geneva, Switzerland, 2018, https://www.who.int/news-room/fact-sheets/detail/cancer/.

[4] V. Srivastava, A. S. Negi, J. K. Kumar, M. M. Gupta, and S. P. S. Khanuja, "Plant-based anticancer molecules: a 
chemical and biological profile of some important leads," Bioorganic \& Medicinal Chemistry, vol. 13, no. 21, pp. 5892-5908, 2005.

[5] S. Sau, H. O. Alsaab, S. K. Kashaw, K. Tatiparti, and A. K. Iyer, "Advances in antibody-drug conjugates: a new era of targeted cancer therapy," Drug Discovery Today, vol. 22, no. 10, pp. 1547-1556, 2017.

[6] P. M. P. Ferreira and C. Pessoa, "Molecular biology of human epidermal receptors, signaling pathways and targeted therapy against cancers: new evidences and old challenges," Brazilian Journal of Pharmaceutical Sciences.vol. 53, pp. 1-17, 2017.

[7] V. Ferrari and D. J. Cutler, "Uptake of chloroquine by human erythrocytes," Biochemical Pharmacology, vol. 39, no. 4, pp. 753-762, 1990.

[8] M. A. Travassos and M. K. Laufer, "Resistance to antimalarial drugs: molecular, pharmacologic, and clinical considerations," Pediatric Research, vol. 65, pp. 64-70, 2019.

[9] S. D’Alessandro, D. Scaccabarozzi, L. Signorini et al., "The use of antimalarial drugs against viral infection," Microorganisms, vol. 8, p. 85, 2020.

[10] C. Huang, Y. Wang, X. Li et al., "Clinical features of patients infected with 2019 novel coronavirus in Wuhan, China," The Lancet, vol. 395, pp. 497-506, Article ID 10223, 2020.

[11] S. Arshad, P. Kilgore, Z. S. Chaudhry et al., "Treatment with hydroxychloroquine, azithromycin, and combination in patients hospitalized with COVID-19," International Journal of Infectious Diseases, vol. 97, pp. 396-403, 2020.

[12] Z. Wang, Q. Wang, T. He et al., "The combination of artesunate and carboplatin exerts a synergistic anti-tumour effect on non-small cell lung cancer," Clinical and Experimental Pharmacology and Physiology, vol. 47, no. 6, pp. 1083-1091, 2020.

[13] F. Pammolli, L. Magazzini, and M. Riccaboni, "The productivity crisis in pharmaceutical R\&D," Nature Reviews Drug Discovery, vol. 10, no. 6, pp. 428-438, 2011.

[14] A. S. Brown and C. J. Patel, "A standard database for drug repositioning," Scientific Data, vol. 4, Article ID 170029, 2017.

[15] C. Mottini, F. Napolitano, Z. Li, X. Gao, and L. Cardone, "Computer-aided drug repurposing for cancer therapy: approaches and opportunities to challenge anticancer targets," Seminars in Cancer Biology, vol. 68, pp. 59-74, 2019.

[16] P. M. P. Ferreira, P. M. D. Costa, A. D. M. Costa et al., "Cytotoxic and toxicological effects of phthalimide derivatives on tumor and normal murine cells," Anais da Academia Brasileira de Ciências, vol. 87, no. 1, pp. 313-330, 2015.

[17] M. M. Kian, A. Haghi, M. Salami et al., "Arsenic trioxide and thalidomide combination induce autophagy along with apoptosis in acute myeloid cell lines," Cell Journal, vol. 22, pp. 193-202, 2020.

[18] F. Jiang, H. S. Xing, W. Y. Chen et al., "Itraconazole inhibits proliferation of pancreatic cancer cells through activation of Bak-1," Journal of Cellular Biochemistry, vol. 120, no. 3, pp. 4333-4341, 2019.

[19] T. Sun, W. Yang, S. M. Toprani et al., "Induction of immunogenic cell death in radiation-resistant breast cancer stem cells by repurposing anti-alcoholism drug disulfiram," Cell Communication and Signaling, vol. 18, no. 1, p. 36, 2020.

[20] C. Xia, R. Chen, J. Chen et al., "Combining metformin and nelfinavir exhibits synergistic effects against the growth of human cervical cancer cells and xenograft in nude mice," Scientific Reports, vol. 7, Article ID 43373, 2017.
[21] A. Das, D. Durrant, C. Mitchell, P. Dent, S. K. Batra, and R. C. Kukreja, "Sildenafil (Viagra) sensitizes prostate cancer cells to doxorubicin-mediated apoptosis through CD95," Oncotarget, vol. 7, no. 4, pp. 4399-4413, 2016.

[22] L. K. Rushworth, K. Hewit, S. Munnings-Tomes et al., "Repurposing screen identifies mebendazole as a clinical candidate to synergise with docetaxel for prostate cancer treatment," British Journal of Cancer, vol. 122, no. 4, pp. 517-527, 2020.

[23] F. Yuan, C. Cheng, F. Xiao, H. Liu, S. Cao, and G. Zhou, "Inhibition of mTORC1/P70S6K pathway by metformin synergistically sensitizes acute myeloid leukemia to Ara-C," Life Sciences, vol. 243, Article ID 117276, 2020.

[24] J. Sun, J. Piao, N. Li, Y. Yang, K.-Y. Kim, and Z. Lin, "Valproic acid targets HDAC1/2 and HDAC1/PTEN/Akt signalling to inhibit cell proliferation via the induction of autophagy in gastric cancer," FEBS Journal, vol. 287, 2019.

[25] J. P. Gil and S. Krishna, "Pfmdr1 (Plasmodium falciparum multidrug drug resistance gene 1): a pivotal factor in malaria resistance to artemisinin combination therapies," Expert Review of Anti-infective Therapy, vol. 15, no. 6, pp. 527-543, 2017.

[26] E. G. Tse, M. Korsik, and M. H. Todd, "The past, present and future of anti-malarial medicines," Malaria Journal, vol. 18, p. 93, 2019.

[27] World Health Organization (WHO), World Health Organization Model List of Essential Medicines: 21st List, World Health Organization, Geneva, Switzerland, 2019, https:// apps.who.int/iris/handle/10665/325771/.

[28] D. J. Wallace, M. Linker-Israeli, S. Hyun, J. R. Klinenberg, and V. Stecher, "The effect of hydroxychloroquine therapy on serum levels of immunoregulatory molecules in patients with systemic lupus erythematosus," Journal of Rheumatology, vol. 21, pp. 375-376, 1994.

[29] I. Ben-Zvi, S. Kivity, P. Langevitz, and Y. Shoenfeld, "Hydroxychloroquine: from malaria to autoimmunity," Clinical Reviews in Allergy and Immunology, vol. 42, no. 2, pp. 145-153, 2012.

[30] E. Schrezenmeier and T. Dörner, "Mechanisms of action of hydroxychloroquine and chloroquine: implications for rheumatology," Nature Reviews Rheumatology, vol. 16, no. 3, pp. 155-166, 2020.

[31] S. Ohkuma and B. Poole, "Fluorescence probe measurement of the intralysosomal $\mathrm{pH}$ in living cells and the perturbation of $\mathrm{pH}$ by various agents," Proceedings of the National Academy of Sciences, vol. 75, no. 7, pp. 3327-3331, 1978.

[32] S. Wunsch, C. P. Sanchez, M. Gekle, L. Große-Wortmann, J. Wiesner, and M. Lanzer, "Differential stimulation of the $\mathrm{Na}^{+} / \mathrm{H}^{+}$exchanger determines chloroquine uptake in Plasmodium falciparum," Journal of Cell Biology, vol. 140, no. 2, pp. 335-345, 1998.

[33] M. Wibo and B. Poole, "Protein degradation in cultured cells. II. The uptake of chloroquine by rat fibroblasts and the inhibition of cellular protein degradation and cathepsin B1," Journal of Cell Biology, vol. 63, no. 2, pp. 430-440, 1974.

[34] V. B. Randolph, G. Winkle, and V. Stollar, "Acidotropic amines inhibit proteolytic processing of flavivirus prM protein," Virology, vol. 174, no. 2, pp. 450-458, 1990.

[35] A. Savarino, J. R. Boelaert, A. Cassone, G. Majori, and R. Cauda, "Effects of chloroquine on viral infections: an old drug against today's diseases?” The Lancet Infectious Diseases, vol. 3, no. 11, pp. 722-727, 2003.

[36] P. Boya, R.-A. Gonzalez-Polo, D. Poncet et al., "Mitochondrial membrane permeabilization is a critical step of 
lysosome-initiated apoptosis induced by hydroxychloroquine," Oncogene, vol. 22, no. 25, pp. 3927-3936, 2003.

[37] Y. Geng, L. Kohli, B. J. Klocke, and K. A. Roth, "Chloroquine-induced autophagic vacuole accumulation and cell death in glioma cells is p53 independent," Neuro-Oncology, vol. 12, pp. 473-481, 2010.

[38] J. A. Ratikan, J. W. Sayre, and D. Schaue, "Chloroquine engages the immune system to eradicate irradiated breast tumors in mice," International Journal of Radiation Oncology, Biology, Physics, vol. 87, no. 4, pp. 761-768, 2013.

[39] R. Thomé, S. C. P. Lopes, F. T. M. Costa, and L. Verinaud, "Chloroquine: modes of action of an undervalued drug," Immunology Letters, vol. 153, no. 1-2, pp. 50-57, 2013.

[40] Y. H. Yoon, K. S. Cho, J. J. Hwang, S.-J. Lee, J. A. Choi, and J.-Y. Koh, "Induction of lysosomal dilatation, arrested autophagy, and cell death by chloroquine in cultured ARPE19 cells," Investigative Opthalmology \& Visual Science, vol. 51, no. 11, pp. 6030-6037, 2010.

[41] V. R. Silva, S. P. Neves, L. D. S. Santos, R. B. Dias, and D. P. Bezerra, "Challenges and therapeutic opportunities of autophagy in cancer therapy," Cancers, vol. 12, no. 11, p. $3461,2020$.

[42] P. M. P. Ferreira, R. W. R. Sousa, J. R. O. Ferreira, G. C. G. Militão, and D. P. Bezerra, "Chloroquine and hydroxychloroquine in antitumor therapies based on autophagy-related mechanisms," Pharmacological Research, vol. 168, 2021.

[43] E. L. Kim, R. Wüstenberg, A. Rübsam et al., "Chloroquine activates the p53 pathway and induces apoptosis in human glioma cells," Neuro-Oncology, vol. 12, no. 4, pp. 389-400, 2010.

[44] A. U. Zaidi, J. S. McDonough, B. J. Klocke et al., "Chloroquineinduced neuronal cell death is p53 and Bcl-2 family-dependent but caspase-independent," Journal of Neuropathology \& Experimental Neurology, vol. 60, no. 10, pp. 937-945, 2001.

[45] P. M. P. Ferreira, L. A. R. L. Rodrigues, L. P. D. A. Carnib et al., "Cruciferous vegetables as antioxidative, chemopreventive and antineoplastic functional foods: preclinical and clinical evidences of sulforaphane against prostate cancers," Current Pharmaceutical Design, vol. 24, no. 40, pp. 4779-4793, 2019.

[46] C. R. Loehberg, T. Thompson, M. B. Kastan et al., "Ataxia telangiectasia-mutated and p53 are potential mediators of chloroquine-induced resistance to mammary carcinogenesis," Cancer Research, vol. 67, no. 24, pp. 12026-12033, 2007.

[47] K. H. Maclean, F. C. Dorsey, J. L. Cleveland, and M. B. Kastan, "Targeting lysosomal degradation induces p53dependent cell death and prevents cancer in mouse models of lymphomagenesis," Journal of Clinical Investigation, vol. 118, no. 1 , pp. 79-88, 2008.

[48] C. R. Loehberg, P. L. Strissel, R. Dittrich et al., "Akt and p53 are potential mediators of reduced mammary tumor growth by chloroquine and the mTOR inhibitor RAD001," Biochemical Pharmacology, vol. 83, no. 4, pp. 480-488, 2012.

[49] J. A. Espinoza, A. Zisi, D. C. Kanellis et al., "The antimalarial drug amodiaquine stabilizes p53 through ribosome biogenesis stress, independently of its autophagy-inhibitory activity," Cell Death \& Differentiation, vol. 27, no. 2, pp. 773-789, 2020.

[50] C. Hu, V. R. Solomon, G. Ulibarri, and H. Lee, "The efficacy and selectivity of tumor cell killing by Akt inhibitors are substantially increased by chloroquine," Bioorganic \& $\mathrm{Me}$ dicinal Chemistry, vol. 16, no. 17, pp. 7888-7893, 2008.
[51] R. Rahim and J. S. Strobl, "Hydroxychloroquine, chloroquine, and all-trans retinoic acid regulate growth, survival, and histone acetylation in breast cancer cells," Anti-Cancer Drugs, vol. 20, no. 8, pp. 736-745, 2009.

[52] K. Sasaki, N. H. Tsuno, E. Sunami et al., "Chloroquine potentiates the anti-cancer effect of 5-fluorouracil on colon cancer cells," BMC Cancer, vol. 10, no. 1, p. 370, 2010.

[53] P. Maycotte, S. Aryal, C. T. Cummings, J. Thorburn, M. J. Morgan, and A. Thorburn, "Chloroquine sensitizes breast cancer cells to chemotherapy independent of autophagy," Autophagy, vol. 8, no. 2, pp. 200-212, 2012.

[54] R. M. Gonçalves, J. P. Agnes, M. Delgobo et al., "Late autophagy inhibitor chloroquine improves efficacy of the histone deacetylase inhibitor SAHA and temozolomide in gliomas," Biochemical Pharmacology, vol. 163, pp. 440-450, 2019.

[55] Y. Xu, H. Yu, H. Qin et al., "Inhibition of autophagy enhances cisplatin cytotoxicity through endoplasmic reticulum stress in human cervical cancer cells," Cancer Letters, vol. 314, no. 2, pp. 232-243, 2012.

[56] X. Jiang, W. Lu, X. Shen et al. "Repurposing sertraline sensitizes non-small cell lung cancer cells to erlotinib by inducing autophagy," JCI Insight, vol. 3, no. 1, Article ID e98921, 2018.

[57] S. Qiao, S. Tao, M. Rojo de la Vega et al., "The antimalarial amodiaquine causes autophagic-lysosomal and proliferative blockade sensitizing human melanoma cells to starvationand chemotherapy-induced cell death," Autophagy, vol. 9, no. 12, pp. 2087-2102, 2013.

[58] M. Selvakumaran, R. K. Amaravadi, I. A. Vasilevskaya, and P. J. O’Dwyer, "Autophagy inhibition sensitizes colon cancer cells to antiangiogenic and cytotoxic therapy," Clinical Cancer Research, vol. 19, no. 11, pp. 2995-3007, 2013.

[59] A. K. Abdel-Aziz, S. Shouman, E. El-Demerdash, M. Elgendy, and A. B. Abdel-Naim, "Chloroquine synergizes sunitinib cytotoxicity via modulating autophagic, apoptotic and angiogenic machineries," Chemico-Biological Interactions, vol. 217, pp. 28-40, 2014.

[60] A. Zanotto-Filho, E. Braganhol, K. Klafke et al., "Autophagy inhibition improves the efficacy of curcumin/temozolomide combination therapy in glioblastomas," Cancer Letters, vol. 358, no. 2, pp. 220-231, 2015.

[61] X. Hou, C. Yang, L. Zhang et al., "Killing colon cancer cells through PCD pathways by a novel hyaluronic acid-modified shell-core nanoparticle loaded with RIP3 in combination with chloroquine,” Biomaterials, vol. 124, pp. 195-210, 2017.

[62] H. Huang, J. Song, Z. Liu, L. Pan, and G. Xu, "Autophagy activation promotes bevacizumab resistance in glioblastoma by suppressing Akt/mTOR signaling pathway," Oncology Letters, vol. 15, no. 2, pp. 1487-1494, 2018.

[63] D. Wang, J. Huang, X. Wang, Y. Yu, H. Zhang, Y. Chen et al., "The eradication of breast cancer cells and stem cells by 8hydroxyquinoline-loaded hyaluronan modified mesoporous silica nanoparticle-supported lipid bilayers containing docetaxel," Biomaterials, vol. 34, no. 31, pp. 7662-7673, 2013.

[64] K. Wang, X. Wang, Y. Hou, H. Zhou, K. Mai, and G. He, "Apoptosis of cancer cells is triggered by selective crosslinking and inhibition of receptor tyrosine kinases," Communications Biology, vol. 2, no. 1, p. 231, 2019.

[65] S. M. Weber, J.-M. Chen, and S. M. Levitz, "Inhibition of mitogen-activated protein kinase signaling by chloroquine," The Journal of Immunology, vol. 168, no. 10, pp. 5303-5309, 2002. 
[66] S. R. Yoshii and N. Mizushima, "Monitoring and measuring autophagy," International Journal of Molecular Sciences, vol. 18, no. 9, p. 1865, 2017.

[67] B. Pasquier, "Autophagy inhibitors," Cellular and Molecular Life Sciences, vol. 73, no. 5, pp. 985-1001, 2016.

[68] Y.-T. Wu, H.-L. Tan, G. Shui et al., "Dual role of 3-methyladenine in modulation of autophagy via different temporal patterns of inhibition on class I and III phosphoinositide 3kinase," Journal of Biological Chemistry, vol. 285, no. 14, pp. 10850-10861, 2010.

[69] S. Christensen, B. Van der Roest, N. Besselink et al., "5Fluorouracil treatment induces characteristic $\mathrm{T}>\mathrm{G}$ mutations in human cancer," Nature Communications, vol. 10, no. 1, p. 4571, 2019.

[70] L. Sun, H. Wang, Z. Wang et al., "Mixed lineage kinase domain-like protein mediates necrosis signaling downstream of RIP3 kinase," Cell, vol. 148, no. 1-2, pp. 213-227, 2012.

[71] W. Chen, Z. Zhou, L. Li et al., "Diverse sequence determinants control human and mouse receptor interacting protein 3 (RIP3) and mixed lineage kinase domain-like (MLKL) interaction in necroptotic signaling," Journal of Biological Chemistry, vol. 288, no. 23, pp. 16247-16261, 2013.

[72] T. A. Sohn, R. Bansal, G. H. Su, K. M. Murphy, and S. E. Kern, "High-throughput measurement of the TP53 response to anticancer drugs and random compounds using a stably integrated TP53-responsive luciferase reporter," Carcinogenesis, vol. 23, no. 6, pp. 949-958, 2002.

[73] E. Calo, R. A. Flynn, L. Martin, R. C. Spitale, H. Y. Chang, and J. Wysocka, "RNA helicase DDX21 coordinates transcription and ribosomal RNA processing," Nature, vol. 518, no. 7538, pp. 249-253, 2015.

[74] Q. Zhou, M. A. McCracken, and J. S. Strobl, "Control of mammary tumor cell growth in vitro by novel cell differentiation and apoptosis agents," Breast Cancer Research and Treatment, vol. 75, no. 2, pp. 107-117, 2002.

[75] Z. K. Melkoumian, A. R. Martirosyan, and J. S. Strobl, "Myc protein is differentially sensitive to quinidine in tumor versus immortalized breast epithelial cell lines," International Journal of Cancer, vol. 102, no. 1, pp. 60-69, 2002.

[76] A. R. Martirosyan, R. Rahim-Bata, A. B. Freeman, C. D. Clarke, R. L. Howard, and J. S. Strobl, "Differentiationinducing quinolines as experimental breast cancer agents in the MCF-7 human breast cancer model," Biochemical Pharmacology, vol. 68, no. 9, pp. 1729-1738, 2004.

[77] Q. Zhou, Z. K. Melkoumian, A. Lucktong, M. Moniwa, J. R. Davie, and J. S. Strobl, "Rapid induction of histone hyperacetylation and cellular differentiation in human breast tumor cell lines following degradation of histone deacetylase-1," Journal of Biological Chemistry, vol. 275, no. 45, pp. 35256-35263, 2000.

[78] G. Das, B. V. Shravage, and E. H. Baehrecke, "Regulation and function of autophagy during cell survival and cell death," Cold Spring Harbor Perspectives in Biology, vol. 4, Article ID 008813, 2012.

[79] R. Ciuffa, T. Lamark, A. K. Tarafder et al., "The selective autophagy receptor p62 forms a flexible filamentous helical scaffold," Cell Reports, vol. 11, no. 5, pp. 748-758, 2015.

[80] C. Fan, W. Wang, B. Zhao, S. Zhang, and J. Miao, "Chloroquine inhibits cell growth and induces cell death in A549 lung cancer cells," Bioorganic \& Medicinal Chemistry, vol. 14, no. 9, pp. 3218-3222, 2006.

[81] S. Choi, Y. Choi, N. T. Dat, C. Hwangbo, J. J. Lee, and J.-H. Lee, "Tephrosin induces internalization and degradation of EGFR and ErbB2 in HT-29 human colon cancer cells," Cancer Letters, vol. 293, no. 1, pp. 23-30, 2010.

[82] C. M. Cabello, S. D. Lamore, W. B. Bair et al., "The redox antimalarial dihydroartemisinin targets human metastatic melanoma cells but not primary melanocytes with induction of NOXA-dependent apoptosis," Investigational New Drugs, vol. 30, no. 4, pp. 1289-1301, 2012.

[83] C. Obua, L. L. Gustafsson, C. Aguttu et al., "Improved efficacy with amodiaquine instead of chloroquine in sulfadoxine/pyrimethamine combination treatment of falciparum malaria in Uganda: experience with fixed-dose formulation," Acta Tropica, vol. 100, no. 1-2, pp. 142-150, 2006.

[84] S. Lu, T. Sung, N. Lin, R. T. Abraham, and B. A. Jessen, "Lysosomal adaptation: how cells respond to lysosomotropic compounds," PLoS One, vol. 12, no. 3, Article ID e0173771, 2017.

[85] A. S. Chauhan, M. Kumar, S. Chaudhary et al., "Trafficking of a multifunctional protein by endosomal microautophagy: linking two independent unconventional secretory pathways," The FASEB Journal, vol. 33, no. 4, pp. 5626-5640, 2019.

[86] P. Rawat, S. Kumar, N. Sheokand, C. I. Raje, and M. Raje, "The multifunctional glycolytic protein glyceraldehyde-3phosphate dehydrogenase (GAPDH) is a novel macrophage lactoferrin receptor," Biochemistry and Cell Biology, vol. 90, no. 3, pp. 329-338, 2012.

[87] M. Mauthe, I. Orhon, C. Rocchi et al., "Chloroquine inhibits autophagic flux by decreasing autophagosome-lysosome fusion,” Autophagy, vol. 14, no. 8, pp. 1435-1455, 2018.

[88] R. Burikhanov, N. Hebbar, S. K. Noothi et al., "Chloroquineinducible Par-4 secretion is essential for tumor cell apoptosis and inhibition of metastasis," Cell Reports, vol. 18, no. 2, pp. 508-519, 2017.

[89] K. Kim, P. Araujo, N. Hebbar et al., "Development of a novel prostate apoptosis response-4 (Par-4) protein entity with an extended duration of action for therapeutic treatment of cancer," Protein Engineering Design and Selection, vol. 32, no. 3, pp. 159-166, 2019.

[90] Y. Zhao, R. Burikhanov, J. Brandon et al., "Systemic Par-4 inhibits non-autochthonous tumor growth," Cancer Biology \& Therapy, vol. 12, no. 2, pp. 152-157, 2011.

[91] R. Burikhanov, T. Shrestha-Bhattarai, S. Qiu et al., "Novel mechanism of apoptosis resistance in cancer mediated by extracellular PAR-4," Cancer Research, vol. 73, no. 2, pp. 1011-1019, 2013.

[92] M. L. Goodall, T. Wang, K. R. Martin et al., "Development of potent autophagy inhibitors that sensitize oncogenic BRAF V600E mutant melanoma tumor cells to vemurafenib," Autophagy, vol. 10, no. 6, pp. 1120-1136, 2014.

[93] S. Nadanaciva, S. Lu, D. F. Gebhard, B. A. Jessen, W. D. Pennie, and Y. Will, "A high content screening assay for identifying lysosomotropic compounds," Toxicology in Vitro, vol. 25, no. 3, pp. 715-723, 2011.

[94] R. Logan, A. C. Kong, E. Axcell, and J. P. Krise, “Aminecontaining molecules and the induction of an expanded lysosomal volume phenotype: a structure-activity relationship study," Journal of Pharmaceutical Sciences, vol. 103, no. 5, pp. 1572-1580, 2014.

[95] A. R. Choi, J. H. Kim, Y. H. Woo, H. S. Kim, and S. Yoon, "Anti-malarial drugs primaquine and chloroquine have different sensitization effects with anti-mitotic drugs in resistant cancer cells," Anticancer Research, vol. 36, no. 4, pp. 1641-1648, 2016. 
[96] C. B. Braga, A. C. Martins, A. D. Cayotopa et al., "Side effects of chloroquine and primaquine and symptom reduction in malaria endemic area (Mâncio Lima, Acre, Brazil)," Interdisciplinary Perspectives on Infectious Diseases, vol. 2015, Article ID 346853, 7 pages, 2015.

[97] A. Srinivasa, S. Tosounidou, and C. Gordon, "Increased incidence of gastrointestinal side effects in patients taking hydroxychloroquine: a brand-related issue?" Journal of Rheumatology, vol. 44, p. 398, 2017.

[98] Spanish Agency of Drug and Health Products and Ministry of Health, "Chloroquine/hydroxychloroquine: precautions and vigilance of possible adverse reactions in patients with COVID-19," 2020, http://www.aemps.gob.es.

[99] M. G. S. Borba, F. F. A. Val, V. S. Sampaio et al., "Effect of high vs. low doses of chloroquine diphosphate as adjunctive therapy for patients hospitalized with severe acute respiratory syndrome coronavirus 2 (SARS-CoV-2) infection: a randomized clinical trial," JAMA Network Open, vol. 3, no. 4, Article ID e208857, 2020.

[100] J. M. Molina, C. Delaugerre, J. L. Goff et al., "No evidence of rapid antiviral clearance or clinical benefit with the combination of hydroxychloroquine and azithromycin in patients with severe COVID-19 infection," Medecine et Maladies Infectieuses, vol. 50, no. 4, p. 384, 2020.

[101] E. S. Rosenberg, E. M. Dufort, T. Udo et al., "Association of treatment with hydroxychloroquine or azithromycin with in-hospital mortality in patients with COVID-19 in New York state," Journal of the American Medical Association, vol. 323, no. 24, pp. 2493-2502, 2020.

[102] A. K. Singh, A. Singh, A. Shaikh, R. Singh, and A. Misra, "Chloroquine and hydroxychloroquine in the treatment of COVID-19 with or without diabetes: a systematic search and a narrative review with a special reference to India and other developing countries," Diabetes \& Metabolic Syndrome: Clinical Research Reviews, vol. 14, no. 3, pp. 241-246, 2020.

[103] C. Rempenault, B. Combe, T. Barnetche et al., "Metabolic and cardiovascular benefits of hydroxychloroquine in patients with rheumatoid arthritis: a systematic review and meta-analysis," Annals of the Rheumatic Diseases, vol. 77, no. 1, pp. 98-103, 2018.

[104] M. C. Figueiredo, C. C. C. T. Atherino, C. V. Monteiro, and R. A. Levy, "Antimaláricos e Ototoxicidade," Revista Brasileira de Reumatologia, vol. 44, no. 3, pp. 212-214, 2004.

[105] J. Ducharme and R. Farinotti, "Clinical pharmacokinetics and metabolism of chloroquine. Focus on recent advancements," Clinical Pharmacokinetics, vol. 31, no. 4, pp. 257-274, 1996.

[106] A. Jorge, C. Ung, L. H. Young, R. B. Melles, and H. K. Choi, "Hydroxychloroquine retinopathy-implications of research advances for rheumatology care," Nature Reviews. Rheumatology, vol. 14, pp. 693-703, 2018.

[107] Y. Momose, S. Arai, H. Eto, M. Kishimoto, and M. Okada, "Experience with the use of hydroxychloroquine for the treatment of lupus erythematosus," The Journal of Dermatology, vol. 40, no. 2, pp. 94-97, 2013.

[108] L. S. Leung, J. W. Neal, H. A. Wakelee, L. V. Sequist, and M. F. Marmor, "Rapid onset of retinal toxicity from highdose hydroxychloroquine given for cancer therapy," American Journal of Ophthalmology, vol. 160, pp. 799-805, 2015.

[109] M. F. Marmor, U. Kellner, T. Y. Y. Lai, R. B. Melles, and W. F. Mieler, "American academy of ophthalmology. recommendations on screening for chloroquine and hydroxychloroquine retinopathy (2016 revision)," Ophthalmology, vol. 123, no. 6, pp. 1386-1394, 2016.

[110] A. J. McLachlan, D. J. Cutler, and S. E. Tett, "Plasma protein binding of the enantiomers of hydroxychloroquine and metabolites," European Journal of Clinical Pharmacology, vol. 44, pp. 481-484, 1993.

[111] I. W. Wainer, J. C. Chen, H. Parenteau et al., "Distribution of the enantiomers of hydroxychloroquine and its metabolites in ocular tissues of the rabbit after oral administration of racemic hydroxychloroquine," Chirality, vol. 6, no. 4, pp. 347-354, 1994.

[112] S. Periyasamy-Thandavan, M. Jiang, Q. Wei, R. Smith, X.-M. Yin, and Z. Dong, "Autophagy is cytoprotective during cisplatin injury of renal proximal tubular cells," Kidney International, vol. 74, no. 5, pp. 631-640, 2008.

[113] L. L. Gustafsson, O. Walker, G. Alván et al., "Disposition of chloroquine in man after single intravenous and oral doses," British Journal of Clinical Pharmacology, vol. 15, no. 4, pp. 471-479, 1983.

[114] D. J. Cutler, A. C. MacIntyre, and S. E. Tett, "Pharmacokinetics and cellular uptake of 4-aminoquinoline antimalarials," Basis for Variability of Response to Anti-Rheumatic Drugs, vol. 24, pp. 142-157, 1988.

[115] K. P. Collins, K. M. Jackson, and D. L. Gustafson, "Hydroxychloroquine: a physiologically-based pharmacokinetic model in the context of cancer-related autophagy modulation," Journal of Pharmacology and Experimental Therapeutics, vol. 365, no. 3, pp. 447-459, 2018.

[116] O. Walker, D. J. Birkett, G. Alván, L. Gustafsson, and F. Sjoqvist, "Characterization of chloroquine plasma protein binding in man," British Journal of Clinical Pharmacology, vol. 15, no. 3, pp. 375-377, 1983.

[117] B. R. Moore, M. Page-Sharp, J. R. Stoney, K. F. Ilett, J. D. Jago, and K. T. Batty, "Pharmacokinetics, pharmacodynamics, and allometric scaling of chloroquine in a murine malaria model," Antimicrobial Agents and Chemotherapy, vol. 55, no. 8, pp. 3899-3907, 2011.

[118] S. L. Rawe and C. McDonnell, "The cinchona alkaloids and the aminoquinolines," in Antimalarial Agents-Design and Mechanism of Action, G. L. Patrick, Ed., Elsevier, Amsterdam, Netherlands, pp. 65-98, 2020.

[119] A. B. Cavalcanti, F. G. Zampieri, R. G. Rosa et al., "Hydroxychloroquine with or without azithromycin in mildto-moderate COVID-19," New England Journal of Medicine, vol. 383 , no. 21,2020 .

[120] J. Sotelo, E. Briceño, and M. A. López-González, “Adding chloroquine to conventional treatment for glioblastoma multiforme: a randomized, double-blind, placebo-controlled trial," Annals of Internal Medicine, vol. 144, no. 5, pp. 337-343, 2006.

[121] L. L. Rojas-Puentes, M. Gonzalez-Pinedo, A. Crismatt et al., "Phase II randomized, double-blind, placebo-controlled study of whole-brain irradiation with concomitant chloroquine for brain metastases," Radiation Oncology, vol. 8, no. 1, p. 209, 2013.

[122] M. R. Rosenfeld, X. Ye, J. G. Supko et al., "A phase I/II trial of hydroxychloroquine in conjunction with radiation therapy and concurrent and adjuvant temozolomide in patients with newly diagnosed glioblastoma multiforme," Autophagy, vol. 10, no. 8, pp. 1359-1368, 2014.

[123] S. B. Goldberg, J. G. Supko, J. W. Neal et al., "A phase I study of erlotinib and hydroxychloroquine in advanced non-smallcell lung cancer," Journal of Thoracic Oncology, vol. 7, no. 10, pp. 1602-1608, 2012. 
[124] D. Mahalingam, M. Mita, J. Sarantopoulos et al., "Combined autophagy and HDAC inhibition: a phase I safety, tolerability, pharmacokinetic, and pharmacodynamic analysis of hydroxychloroquine in combination with the HDAC inhibitor vorinostat in patients with advanced solid tumors," Autophagy, vol. 10, no. 8, pp. 1403-1414, 2014.

[125] A. Arnaout, S. J. Robertson, G. R. Pond et al., "A randomized, double-blind, window of opportunity trial evaluating the effects of chloroquine in breast cancer patients," Breast Cancer Research and Treatment, vol. 178, no. 2, pp. 327-335, 2019.

[126] R. Rangwala, Y. C. Chang, J. Hu et al., "Combined MTOR and autophagy inhibition: phase I trial of hydroxychloroquine and temsirolimus in patients with advanced solid tumors and melanoma," Autophagy, vol. 10, no. 8, pp. 1391-1402, 2014.

[127] D. T. Vogl, E. A. Stadtmauer, K.-S. Tan et al., "Combined autophagy and proteasome inhibition: a phase 1 trial of hydroxychloroquine and bortezomib in patients with relapsed/refractory myeloma," Autophagy, vol. 10, no. 8, pp. 1380-1390, 2014.

[128] B. M. Wolpin, D. A. Rubinson, X. Wang et al., "Phase II and pharmacodynamic study of autophagy inhibition using hydroxychloroquine in patients with metastatic pancreatic adenocarcinoma," The Oncologist, vol. 19, no. 6, pp. 637-638, 2014. 